Co-translational misfolding in epilepsy

8 Janire Urrutia:

9 Alejandra Aguado: Alvaro Villarroel ${ }^{1 *}$ 48940 Leioa, Spain 48940 Leioa, Spain domain

\title{
AN EPILEPSY-CAUSING MUTATION LEADS TO CO-TRANSLATIONAL MISFOLDING
}

Janire Urrutia ${ }^{1,7 \dagger}$, Alejandra Aguado ${ }^{1 \dagger}$, Carolina Gomis-Perez ${ }^{1,8 \dagger}$, Arantza

Muguruza-Montero ${ }^{1}$, Oscar R. Ballesteros ${ }^{2}$, Jiaren Zhang ${ }^{3}$, Eider Nuñez ${ }^{1}$, Covadonga Malo ${ }^{1}$, Hee Jung Chung ${ }^{3}$, Aritz Leonardo ${ }^{4,5}$, Aitor Bergara ${ }^{2,5,6}$ and

Carolina Gomis-Perez:

Arantza Muguruza-Montero:

Oscar R. Ballesteros:

Jiaren Zhang:

Eider Nuñez:

Covadonga Malo:

Hee Jung Chung

Aritz Leonardo:

Aitor Bergara:

Alvaro Villarroel: janire.urrutia@ehu.eus

alejandra.aguado@ehu.eus

carolina.gomisperez@yale.edu

arantza.muguruza.montero@gmail.com

orodriguez049@ikasle.ehu.eus

jzhan118@illinois.edu

enviadero@gmail.com

covadonga.m@gmail.com

chunghj@illinois.edu

aritz.leonardo@ehu.eus

a.bergara@ehu.eus

alvaro.villarroel@csic.es

*Correspondence: alvaro.villarroel@csic.es; Tel.: +34 946013225.

tThese authors contributed equally to this work.

${ }^{1}$ Instituto Biofisika, CSIC-UPV/EHU, 48940 Leioa, Spain

${ }^{2}$ Centro de Física de Materiales CFM, CSIC-UPV/EHU, 20018 Donostia, Spain

${ }^{3}$ Department of Molecular and Integrative Physiology, University of Illinois at

Urbana-Champaign, Urbana, Illinois, 61801, USA

${ }^{4}$ Departamento de Física Aplicada II, Universidad del País Vasco, UPV/EHU,

${ }^{5}$ Donostia International Physics Center, 20018 Donostia, Spain

${ }^{6}$ Departmento de Materia Condensada, Universidad del País Vasco, UPV/EHU,

${ }^{7}$ Current address: Department of Physiology, Faculty of Medicine and Nursery, UPV/EHU, 48940 Leioa, Spain

${ }^{8}$ Current address: Department of Cellular and Molecular Physiology, Yale University School of Medicine, New Haven, CT, USA

Keywords: KCNQ channels, Epilepsy, co-translational folding, calmodulin, IQ 


\section{Abstract}

Protein folding to the native state is particularly relevant in human diseases where inherited mutations lead to structural instability, aggregation and degradation. In general, the amino acid sequence carries all the necessary information for the native conformation, but the vectorial nature of translation can determine the folding outcome. Calmodulin (CaM) recognizes the properly folded Calcium Responsive Domain (CRD) of $\mathrm{K}_{\mathrm{v}} 7.2$ channels. Within the IQ motif (helix A), the W344R mutation found in epileptic patients has negligible consequences for the structure of the complex as monitored by multiple in vitro binding assays and molecular dynamic computations. In silico studies revealed two orientations of the side chain, which are differentially populated by WT and W344R variants. Binding to CaM is impaired when the mutated protein is produced in cellulo but not in vitro, suggesting that this mutation impedes proper folding during translation within the cell by forcing the nascent chain to follow a folding route that leads to a non-native configuration, and thereby generating non-functional ion channels that fail to traffic to proper neuronal compartments.

\section{INTRODUCTION}

Mutations at the KCNQ2 gene underlie early-onset hereditary epilepsy, with different clinical outcomes (including Benign Familial Neonatal Epilepsy, BFNE and Epileptic Encephalopathy type 7, EE7) [3-7]. This gene encodes for $\mathrm{K}_{\mathrm{v}} 7.2$ subunits of tetrameric voltage-dependent potassium $\left(\mathrm{K}^{+}\right)$selective channels, which, combined with $\mathrm{K}_{\mathrm{v}} 7.3$ subunits, underlie non-inactivating $\mathrm{M}$ current. $\mathrm{K}_{\mathrm{v}} 7.2 / \mathrm{K}_{\mathrm{v}} 7.3$ channels are enriched at the plasma membrane of the axon initial segment (AIS) and distal axons [8]. With their characteristic slow voltagedependent kinetics of activation and deactivation, and voltage-dependent opening within the subthreshold range of action potential generation, they are critical for neuronal excitability [9]. A number of pathogenic variants cluster at key functional domains that are involved in voltage sensing, ion conduction, selectivity, gating, or stabilization of binding to the essential co-factor $\mathrm{PIP}_{2}[5$; $10 ; 11]$.

Clusters of pathological variants are also found at the Calcium Responsive Domain (CRD), located intracellularly following the pore gate [5; 12; 13]. The CRD is an autonomously folding hairpin domain formed by two antiparallel alpha helices $[14 ; 15]$, named $A$ and $B$ [16], that run under the 
Co-translational misfolding in epilepsy

76 membrane adjacent to the voltage sensor [17]. These helices are recognized by

77 calmodulin (CaM) [18-21], which confers calcium $\left(\mathrm{Ca}^{2+}\right)$ sensitivity [15; 22-26].

Some mutations in the KCNQ2 gene have been suggested to cause

79 misfolding [27; 28], a mechanism that has been identified in many hereditary

80 diseases [29; 30]. However, little is known on how pathogenic variants located

81 at the CRD affect folding. In this work, we have explored how a $\mathrm{K}_{\mathrm{v}} 7.2$ mutation

82 (W344R) located in helix $A$ of the CRD, found in patients with hereditary

83 epilepsy [1; 31], interferes with channel function. The data reveal that the key

84 mechanism involves the failure to adopt a configuration that can be recognized

85 by CaM in vivo but not in vitro. 
Co-translational misfolding in epilepsy

\section{RESULTS}

\section{Functional characterization of the W344R mutation}

The W344R mutation at the IQ site of helix A does not disturb CaM binding to the autonomously folding calcium responsive domain (CRD) of $\mathrm{K}_{v} 7.2$ channels, yet it abolishes function [1]. This is in contrast to other helix A mutants, for which a clear correlation between CaM binding and function was observed [2](Supplemental Figure 1). To understand this remarkable discrepancy, we re-evaluated its functional properties. In total agreement with previous work [1;31], we found that homomeric W344R channels were not functional (Figure 1A). The impact of this mutant in combination with its partner $\mathrm{K}_{v} 7.3$ and wild type (WT) $\mathrm{K}_{\mathrm{v}} 7.2$ subunits (in a 1:2:1 ratio) to mimic genetic balance has been previously tested, revealing variable effects $[1 ; 31]$. To simplify the paradigm, we tested the impact of $\mathrm{K}_{\mathrm{v}} 7.2$ mutant when combined with $\mathrm{K}_{\mathrm{v}} 7.3$ subunits in a 1:1 ratio (Figure 1 ). $\mathrm{K}_{\mathrm{v}} 7.3$ alone yields negligible currents when expressed in HEK293T cells, whereas robust currents, that are two or three fold larger than from homomeric $\mathrm{K}_{\mathrm{v}} 7.2$ currents, are recorded when combined with WT Kv7.2 subunits in a 1:1 ratio (not shown).

No currents were observed in cells expressing $\mathrm{K}_{\mathrm{v}} 7.3 / \mathrm{K}_{\mathrm{v}} 7.2-\mathrm{W} 344 \mathrm{R}$ heteromers, but, in contrast, robust currents were evoked for the $\mathrm{K}_{\mathrm{v}} 7.2 / \mathrm{K}_{\mathrm{v}} 7.2-$ W344R combination (Figures $1 \mathrm{~A}$ and $1 \mathrm{~B}$ ). There was a modification on the voltage-dependency, as revealed by a statistically significant $\sim 5 \mathrm{mV}$ rightward shift in the current-voltage relationship for the $\mathrm{K}_{\mathrm{v}} 7.2 / \mathrm{K}_{\mathrm{v}} 7.2-\mathrm{W} 344 \mathrm{R}$ arrangement (Figure 1). Co-IP experiments were also consistent with the formation of heteromeric assemblies (Figure 1D). HEK293T cells were co-transfected with Myc-tagged Kv7.2 WT subunits with either CFP-tagged WT or CFP-tagged mutant subunits in a 1:1 ratio. Protein lysates were immunoprecipitated with anti-c-Myc antibody and detected using anti-Kv7.2 antibody, resulting in the appearance of two bands due to the different MW imposed by the tags (Figure 1D). No significant difference could be detected between the relative signal corresponding of Myc-WT (MW 125 kDa) and CFP-tagged WT or W344R subunits (MW $\sim 135 \mathrm{kDa}$ ). 
Co-translational misfolding in epilepsy

\section{The W344R mutation impairs trafficking}

$\mathrm{K}_{v} 7.2$ interaction with $\mathrm{CaM}$ is critical for the exit of $\mathrm{K}_{\mathrm{v}} 7.2 / \mathrm{K}_{\mathrm{v}} 7.3$ channels from the endoplasmic reticulum (ER) and their expression at the axonal surface [8]. To assess the impact on trafficking to the axon initial segment (AIS) and other neuronal regions, surface immunostaining of $\mathrm{K}_{\mathrm{v}} 7.3$ subunits containing an extracellular HA epitope was evaluated [13; 32]. This $K_{v} 7.3$ reporter subunit was co-expressed with CFP-tagged $\mathrm{K}_{\mathrm{v}} 7.2 \mathrm{WT}$ or mutant W344R subunits in embryonic rat hippocampal neurons. As reference, the CFP-tagged $\mathrm{K}_{\mathrm{v}} 7.2-1340 \mathrm{E}$ mutant was included because it precludes CaM binding [32; 33] and, as a consequence, prevents the reporter $\mathrm{K}_{\mathrm{v}} 7.3$ subunit to traffic to the plasma membrane of different neuronal sub-compartments [32]. Plasma membrane expression of $\mathrm{HA}-\mathrm{K}_{\mathrm{v}} 7.3 / \mathrm{K}_{\mathrm{v}} 7.2 \mathrm{WT}$ heteromers were enriched at the AIS and distal axon (Figure 2). However, when Kv7.2 carried the I340E or W344R mutations, the reporter $\mathrm{HA}-\mathrm{K}_{\mathrm{v}} 7.3$ subunit failed to reach the AIS and distal axon (Figure 2). The total signal for both mutant subunits was reduced by about $70 \%$ (supplemental Figures 2 and 3). Except for the relative abundance at the soma (supplemental Figures 2 and 3), the surface expression profile for W344R and I340E mutants were similar (Figure 2), suggesting that neither bind CaM in a cellular in vivo context.

\section{The W344R mutation impairs calmodulin binding in cellulo}

To assess CaM binding in cellulo, the transfer of energy between CaM and $\mathrm{K}_{\mathrm{v}} 7.2$ channels, tagged with CFP (donor) and YFP (acceptor) fluorophores respectively, was monitored in living cells using Förster resonance energy transfer (FRET). This pair of fluorophores exhibits 50\% energy transfer at $\sim 50 \AA$ and produces measurable transfer up to $\sim 80 \AA$. Binding between a ligand and acceptor can be evaluated in cellulo using this approach, with comparable results to in vitro binding assays [34-36]. Cells expressing similar levels of donor and acceptor where included in the analysis (see Materials and Methods). The ratio of the integral of CFP emission divided by the integral of YFP emission isolated after spectral unmixing of confocal images is proportional to FRET efficiency. Compared to WT channels, the FRET index was significantly 
Co-translational misfolding in epilepsy

reduced for W344R subunits $(0.49 \pm 0.090$ for WT vs $0.10 \pm 0.012$ for W344R, Figure 3A).

Four alpha helices designated $A$ through $D$ can be recognized within the intracellular C-terminal domain of every $\mathrm{K}_{\mathrm{v}} 7$ channel [16; 37]. CaM embraces the hairpin formed by helices A and B [14; 38; 39]. The CRD is followed by two alpha helices, $C$ and $D$, which run perpendicular to the membrane [17; 40]. Assembling as either heterotetramer or homotetramer depends on the identity of helix D [37].

To test if the W344R mutation decreases CaM binding to helices $A$ and $B$ of $\mathrm{K}_{\mathrm{v}} 7.2$ in cellulo, CFP-CaM was co-expressed with YFP-tagged C-terminal tail containing helices $A$ through $D$ that forms tetrameric complexes (YFP-ABCD), or with YFP-tagged helices $A$ and $B$ (YFP-AB) that forms monomeric complexes [34]. The transfer of energy was significantly larger when the acceptor was $A B C D$ than when it was $A B$, and, importantly, the FRET index was almost abolished for the W344R mutant proteins (Figure 3A).

We have previously observed FRET in cells expressing helices $A B C D$ (CFP-ABCD + YFP-ABCD) which is related to the ability of the $D$ segment to form tetrameric coiled-coil assemblies [34]. The ABCD resembles a flower bouquet with the coiled-coil helix D corresponding to the pedestal [14]. The transfer of energy between these proteins increases with $\mathrm{CaM}$ overexpression (Figure $3 \mathrm{~B}$ ), suggesting that $\mathrm{CaM}$ promotes a rearrangement of helix $\mathrm{A}$ within the $A B C D$ region [34]. In contrast, the presence of the W344R mutation completely obliterated the FRET response to increased CaM expression, and this FRET response was lower under basal or elevated CaM conditions (Figure $3 \mathrm{~B}$ ), suggesting that the $\mathrm{C}$-terminal region adopted a more relaxed configuration due to the W344R mutation. These results reinforce the proposal that this mutation prevents $\mathrm{CaM}$ binding to the $\mathrm{CRD}$ of $\mathrm{K}_{\mathrm{v}} 7.2$ channels in living cells.

\section{The W344R mutation prevents proper folding during translation}

We have previously shown that the W344R mutation does not disturb CaM binding to the GST-CRD fusion protein using in vitro binding assays, including dansylated-CaM fluorescence emission, Far-Western or Surface 
Plasmon Resonance [1]. The discrepancy between in vitro and in cellulo CaM binding could be explained if the polypeptide follows different folding pathways. We hypothesized that the production and isolation of the GST-CRD fusion protein allowed folding in vitro of the CRD to a native configuration that could be recognized by CaM. To evaluate this, we used a "folding sensor" (Figure 4A) which has been previously described [15]. This sensor contains helices A and B flanked by mTFP1 and mcpVenus florescent reporters at the protein $\mathrm{N}$ - and Cterminal ends, respectively (Figure 4A). Since helices $A$ and $B$ adopt an antiparallel fork configuration, co-expression of CaM brings both fluorophores close to each other, resulting in a FRET index value of 1.70 , defined as the ratio of peak emission at $528 \mathrm{~nm}$ and $492 \mathrm{~nm}$. Addition of the strong chaotropic agent urea at $6 \mathrm{M}$ reduced of the FRET index to 0.55 , which is the same value obtained with mTFP1 alone. Since both mTFP1 and mcpVenus fluorogenic properties are not affected by this treatment, this FRET reduction indicates unfolding of the $A B$ fork (supplemental Figure 4).

Folding in a cellular context in the absence of CaM was assessed in bacteria, since essential folding mechanisms are shared by prokaryotes and eukaryotes [30], and prokaryotes do not express CaM [41]. Most of the expressed folding sensor molecules were insoluble (Figure 5A, left). The material from inclusion bodies was solubilized with $6 \mathrm{M}$ urea, and thereafter the chaotropic agent was removed by dialysis in the presence or absence of CaM (Figure 4). The emission spectra from reconstituted WT and W344R folding sensors were indistinguishable, presenting FRET index values congruent with proper folding when CaM was present (Figures 4B-E). Thus, the W344R mutation is compatible with the adoption of the native $A B$ fork configuration, consistent with the ability of CaM to bind in vitro to the $\mathrm{AB}$ protein [1]. sensors translated in CaM-free bacteria did not display FRET (Figure 5C), suggesting their unfolded nature. To test if the presence of CaM can induce their proper folding, excess purified CaM was added to the soluble fraction. However, no indication of CaM induced folding was observed as the FRET index remained unaltered after up to 24 hours (supplemental Figure 5), 
Co-translational misfolding in epilepsy

212

213

214

215

216

217

218

219

220

221

222

suggesting that the unfolded $A B$ fork was stable and cannot be rescued by in vitro addition of CaM.

When $\mathrm{CaM}$ was co-expressed in bacteria and therefore it was present during translation, a larger fraction of the WT sensors became soluble (Figures $5 \mathrm{~A}$ and $\mathrm{B}$ ) and presented a robust FRET (Figure 5C). In contrast, for the W344R mutant, a large fraction ended up in inclusion bodies (Figures 5A and $5 B$ ), although a small soluble fraction displayed significant FRET index (Figure 5D). This FRET index represented $25 \%$ of that observed for the WT biosensor, suggesting that there was a small proportion of properly folded sensors carrying the W344R mutation.

To assess how the rate of translation affects the outcome, the same experiments were performed lowering the temperature to $18^{\circ} \mathrm{C}$ during the induction of translation, but no significant difference was found compared to $37^{\circ} \mathrm{C}$ (supplemental Figure 6 ).

We exploited the ability of the SecM translational arresting peptide (AP) to act as a force sensor that detects folding of proteins in the ribosomal exit tunnel during translation [42-45]. The SecM AP interacts with the ribosome tunnel and detains protein synthesis, unless external force acting on the polypeptide chain "pulls-out" the AP, thereby relieving translational arrest [42]. Such pulling force can be induced by cotranslational protein folding [42; 43], with equivalent results in vitro and in cellulo [44], and identifies the same cotranslational folding transitions as do other methods, such as real-time FRET, photoinduced electron transfer, and NMR [46]. The Kv7.2 CRD was cloned upstream of the SecM arresting peptide sequence with tethers of increasing length and flanked by mTFP1 and mcpVenus fluorescent reporters in the $\mathrm{N}$ and C-terminus respectively (Figure $5 \mathrm{E}$ ). In this paradigm, if the protein is stalled, the result is an mTFP1-tagged truncated protein. In contrast, if CaM participates in folding of the CRD during translation and the full-length protein is translated; fluorescent signals from both mTFP1 and mcpVenus could be recorded (see supplemental Figure 7). By measuring the stalling efficiency (as fraction of full-length reporter protein) for a series of constructs of increasing 
243 tether length, it is possible to identify when the protein starts to fold during translation $[45 ; 46]$.

Therefore, we used the ratio of emission at the peak wavelength for mcpVenus and for mTFP1 to assess the fraction of full-length reporter protein (Figure 5E). The ratio was very low when WT or W344R AP reporters were expressed alone, but there was a robust signal for WT when expressed in the presence of CaM. This suggests that CaM exerts a fundamental role for CRD folding during translation. The index decreased as the length of the tether increased, reminiscent of profiles described for other proteins [44]. Although lower than WT, CaM also increased the translation of full-length W344R reporter, suggesting that a fraction of the W344R mutant reporter was folding during translation when CaM was present. These results are concordant with FRET observed for the $A B$ sensor (Figures $5 C$ and $5 D$ ).

\section{Two orientations for tryptophan and arginine at position 344}

To explore the stability of the W344R CaM/Kv7.2-AB complex in silico, binding affinities were derived using the Rosetta Flex ddG software. Random changes in the backbone angles near the site of interest are introduced, generating a trajectory of structures which are classified with respect to their resulting energy values. Afterwards, each of these random structures are ruled out or accepted, according to a Metropoli Montecarlo criteria, and resulting in small winning population of the energetically most stable configurations.

We found that in most of the cases the side chain of tryptophan at position 344 is oriented towards $\mathrm{CaM}$ in the structures of the $\mathrm{AB} / \mathrm{CaM}$ complex of different $\mathrm{K}_{\mathrm{v}} 7$ subunits [14; 15; 20; 38; 40]. Interestingly, detailed visualization of the final accepted trajectory snapshots of Rosetta moves revealed a small population (1.6\% for WT and $3.4 \%$ for W344R) in which the side chain became tilted $(\mathrm{T})$ towards the rest of the A helix, instead of targeting the CaM C-lobe, as it appears in the native (N) WT structure (Figure 6A).

The computed value of the $\Delta \Delta G$ for $\mathrm{W} 344 \mathrm{R}$ was $5.1 \mathrm{kcal} / \mathrm{mol}$. This is a common value of a destabilizing mutation [5; 47; 48](supplemental Figure 8), 273 suggesting that CaM binding to W344R should be disrupted, which seems 
274 inconsistent with the actual in vitro binding data (supplemental Figure 8). To unravel this inconsistency, we next computed all-atom energy.

To elaborate a hypothesis on the mechanism underlying the differential effect of the W344R mutation in vitro and in cellulo, we determined which orientation is the most stable in absence of CaM. For this purpose, all-atom molecular dynamics (MD) simulations of the hA-TW-hB segment not engaged with CaM in a water cubic box for both WT and mutant were performed. After equilibration, the tryptophan residue at position 344 converges to the $\mathrm{N}$ position, whereas the arginine residue adopted the $T$ orientation, and subsequent MD simulations were computed from these starting positions, respectively (Figure $6 \mathrm{~B})$. In WT, tryptophan remains stable in the $\mathrm{N}$ configuration during $100 \mathrm{~ns}$, and no transitions to the $\mathrm{T}$ state were observed. Furthermore, when W344 was forced to start from the $\mathrm{T}$ configuration, it transited to the $\mathrm{N}$ state in a few ns and remained there, confirming that the $\mathrm{N}$ configuration is more stable (see supplemental Figure 9). The energy needed to overcome the conformational change of the side chain from $\mathrm{N}$ to $\mathrm{T}$ is higher for the WT, which may underlie its inability to explore the T configuration. In W344R mutant, transitions between the two states were observed for the arginine residue, remaining more time in $\mathrm{T}$ (Figure 6B), suggesting that the energy barrier between the two states in the absence of CaM is smaller. Since W344R remains more time in $\mathrm{T}$ than in $\mathrm{N}$, we conclude that the T configuration is the most stable when not engaged to CaM. To represent this information from an energetic perspective, the potential of mean force for the angles formed by the side chain and backbone were computed using the weighted histogram analysis method [49]. Figure 6B shows that the WT has a defined potential well around the $\mathrm{N}$ configuration. Conversely, W344R has its lowest energy configuration in $\mathrm{T}$ and the potential barrier between the two states is lower, so that it is more common to find the $T$ configuration but the $\mathrm{N}$ is not energetically banned.

To identify which configuration of the mutated $\mathrm{K}_{\mathrm{v}} 7.2$ channel favors binding to CaM, the average of the non-bonding interaction energy between the residue W344R and CaM was computed using the CHARMM36 all-atom energy function for all the snapshots of Rosetta trajectories. In W344R mutant, the energy for $\mathrm{T}$ configuration was $-16 \mathrm{kcal} / \mathrm{mol}$, and that for the $\mathrm{N}$ configuration 
Co-translational misfolding in epilepsy

307 was $-76 \mathrm{kcal} / \mathrm{mol}$. In WT, the computed energies were $-10 \mathrm{kcal} / \mathrm{mol}$ and -20

$308 \mathrm{kcal} / \mathrm{mol}$ for the $\mathrm{T}$ and $\mathrm{N}$ configurations, respectively. These results suggest that

309 the $\mathrm{N}$ configuration is more compatible with CaM binding than the $\mathrm{T}$

310 configuration, and that arginine is more stable than tryptophan when helix $A$ is

311 in complex with CaM. This may explain the ability of both WT and W344R to

312 bind CaM in vitro (see supplemental Figure 8). 
Co-translational misfolding in epilepsy

\section{DISCUSSION}

The analysis of mutations at helix $A$ of the CRD of $K_{v} 7.2$ subunits has revealed an obvious relationship between $\mathrm{CaM}$ binding and function: subunits that do not bind CaM in vitro and in cellulo are retained at the ER, and channel function is concomitantly abolished [2; 13;32; 33](supplemental Figure 1).

The W344R mutation found in patients with hereditary epilepsy $[1 ; 31]$ is unique because it does not affect $\mathrm{CaM}$ binding to the CRD of $\mathrm{K}_{v} 7.2$ in vitro [1](supplemental Figure 8), but abolish current and surface expression of $\mathrm{K}_{v} 7.2$ channels (Figures 1-2). Two main hypotheses could explain this striking deviation from the common trend. One possibility is that this mutation may lock the gate of the channel in a closed state, for example, by impeding the expansion of the inner gate formed by the $\mathbf{S} 6$ bundle crossing that is directly attached to helix A. Alternatively, this mutation may prevent CaM binding within the cellular environment, but not in in vitro assays (supplemental Figure 8).

Here, we show that the W344R mutation prevents FRET between CaM and $K_{v} 7.2$ subunits in cells. In addition, the tetrameric assembly of the four A-D helices in mutant $\mathrm{K}_{\mathrm{v}} 7.2$ [34] becomes insensitive to CaM abundance (Figure 3). Therefore, the W344R mutation disrupts CaM binding to the isolated CDR or the full-length channel in living cells. Importantly, our FRET sensor that detects folding of the antiparallel $A B$ fork, and the assessment of release from stalled ribosomes, revealed that the W344R mutation disrupts CRD folding during translation in the presence of CaM in cellulo (Figures 4-5), indicating that the majority of the W344R mutant proteins fail to adopt a properly folded state during translation in living cells. Our results indicate that the presence of CaM during translation can be considered essential for proper folding of $\mathrm{K}_{v} 7 \mathrm{CRD}$, in agreement with previous proposals [50; 51].

What are the differential properties between tryptophan and arginine that lead to the failure of W344R to adopt a configuration that can be recognized by $\mathrm{CaM}$ in cellulo? We discovered two possible orientations ( $\mathrm{N}$ and $\mathrm{T}$ ) for the residue at position 344 (Figure 6). When the CRD is not in complex with CaM, the adoption of the $T$ orientation in WT CRD is very rare, concordant with atomic models $[14 ; 15 ; 20 ; 38 ; 40]$, whereas the $T$ configuration is stable and 
preferred over the $\mathrm{N}$ configuration for W344R CRD (Figure 6). However, when helix $\mathrm{A}$ is in complex with CaM, the local interactions with the arginine residue in the W344R mutant are more favorable than the tryptophan residue in the WT (Figure 6), consistent with in vitro binding data that demonstrates similar CaM interaction with WT and W344R CRD [1](see supplemental Figure 8).

We speculate that the vectorial nature of translation of the mutated $\mathrm{K}_{\mathrm{v}} 7.2$ channel, with the subsequent decrease on its available configurational space, could favor the T configuration of the W344R side chain during the transit of the nascent chain in the ribosomal tunnel. Consequently, after the nascent chain emerges from the ribosome in a eukaryotic cellular environment with abundance of CaM molecules, the W344R residue might remain in the metastable $\mathrm{T}$ configuration, which could prevent the proper binding between CaM and the mutated channel. In addition, this configuration may alter interactions with molecular chaperones or favor degradation. On the other hand, in vitro experiments might enlarge the accessible configurations for the W344R side chain, allowing it to find the most stable $\mathrm{N}$ configuration when interacting with CaM, favoring the mutated $\mathrm{K}_{\mathrm{v}} 7.2$ channel to properly bind CaM. The key difference is that in vivo the N-terminal portion can start folding before the $\mathrm{C}$ terminal portion has been synthesized or is still within the ribosomal tunnel. In contrast, refolding of the full CRD in vitro can begin via interactions anywhere along the peptide chain [52]. In summary, the adoption of the $T$ orientation favored by the W344R mutation may represent a kinetic trap in the path to a native fold [53], although more data is required to fully understand the process.

Genetic protein folding defects could be segregated into two categories: those due to mutations that are unsuited to adopt the native fold and those that can adopt the native structure with the use of chemical chaperons, low temperature or ligands. For instance, the function of the N258S Kv7.2 mutation,

372 located in the extracellular turret just after S5, can be partially recovered with

$373 \mathrm{~K}_{\mathrm{v}} 7.3$ subunits, by culturing cells at lower temperatures or in the presence of the $374 \quad K_{v} 7$-binding drug retigabine [28]. This second group could be divided further into those defects that lead to a weaker or unstable structure, and those that are compatible with a stable native configuration but fail to find the proper folding pathway. The W344R mutant fits readily in this latter category. We are not 
Co-translational misfolding in epilepsy

378

379

380

381

382

383

384

385

386

387

388

389

390

391

392

393

394

395

396

397

398

399

400

401

402

403

404

405

406

407

408

409

aware of any other pathological mutation with these properties and, therefore, this mutant may be the first representative within this group.

A remaining question is when and where does the W344R mutant deviate from the proper folding pathway. Some nascent chains can adopt an alpha helix configuration in the restricted space of the ribosomal tunnel, and can fold into tertiary structures in its vestibule [30]. Analysis of the amino acid sequence of helix A using the Agadir server predicts that both WT and W344R will fail to form a stable alpha helix in solution, with scores of 0.4 and 0.7 (in a 0 to 100 scale), respectively. However, even unstable peptides may form helical structures in some regions of the ribosomal tunnel [54-56]. The vectorial nature of protein synthesis, the spatial constrains and physicochemical properties of the ribosomal tunnel, can guide the folding trajectory of the nascent peptide [30]. Our data and other observations are consistent with the idea that the emerging helix A segment, located at the $\mathrm{N}$-terminus of the CRD, starts to fold before the C-terminal part of the protein is synthesized [57], and will initiate interactions with the CaM C-lobe in the vestibule or outside the ribosome during translation. It is not known if the emerging segment is already folded, or if CaM induces the adoption of an alpha helix. Our data is compatible with the idea that CaM fails to promote alpha helix formation to the mutant W344R nascent chain, whereas in vitro binding is best described by selection of the properly folded molecules [58-60].

In summary, we show here that the autonomously folding calcium responsive domain (CRD) carrying the W344R mutation is not recognized by $\mathrm{CaM}$ in a cellular in vivo context, but it does so after refolding in vitro. This mutation impedes proper folding during translation within the cell by forcing the nascent chain to follow a folding route that leads to non-functional ion channels. Thus, although it carries all the information for the native 3D configuration, it fails to reach it in vivo. Our MD simulations suggest a reasonable hypothesis for the underlying mechanism. Thus, this study provides a mechanistic insight into co-translational folding defects, which may represent a widespread mechanism that contributes to pathophysiology. 
Co-translational misfolding in epilepsy

Author Contributions: A.V. conceived the study and participated in its design and coordination. J.U., A.A., C.G-P., and A.M-M. carried out experiments, contributed to figure preparation, and manuscript preparation. O.R.B., A.M-M., A.B. and A.L. performed in silico analysis, contributed to figure preparation, and manuscript

414 preparation. J.Z. and H.J.C. contributed to neuronal characterization, figure 415 preparation, and manuscript preparation. E.N. and C.M. prepared reagents, and 416 contributed to experimental design and figure preparation. All authors read and approved the final manuscript.

Funding: The Government of the Autonomous Community of the Basque Country (IT1165-19 and KK-2020/00110) and the Spanish Ministry of Science and Innovation (RTI2018-097839-B-100 to A.V. and FIS2016-76617-P to A.B.) and FEDER funds and the United States National institute of Neurological Disorders (NINDS) and Stroke Research Project Grant (R01NS083402 to H.J.C.) provided financial support for this work. E.N. and A.M-M. are supported by predoctoral contracts from the Basque

424 Government administered by University of the Basque Country. C.V. was supported by 425 the Basque Government through a Basque Excellence Research Centre (BERC) grant 426 administered by Fundación Biofisika Bizkaia (FBB) J.U. was partially supported by 427 BERC funds. O.R.B. was supported by the Basque Government through a BERC grant 428 administered by Donostia International Physics Center. J.Z. and H.J.C. was supported by the NINDS Research Project Grant \#R01NS083402 (PI: H.J.C.).

Conflicts of Interest: The authors declare no conflict of interest. 


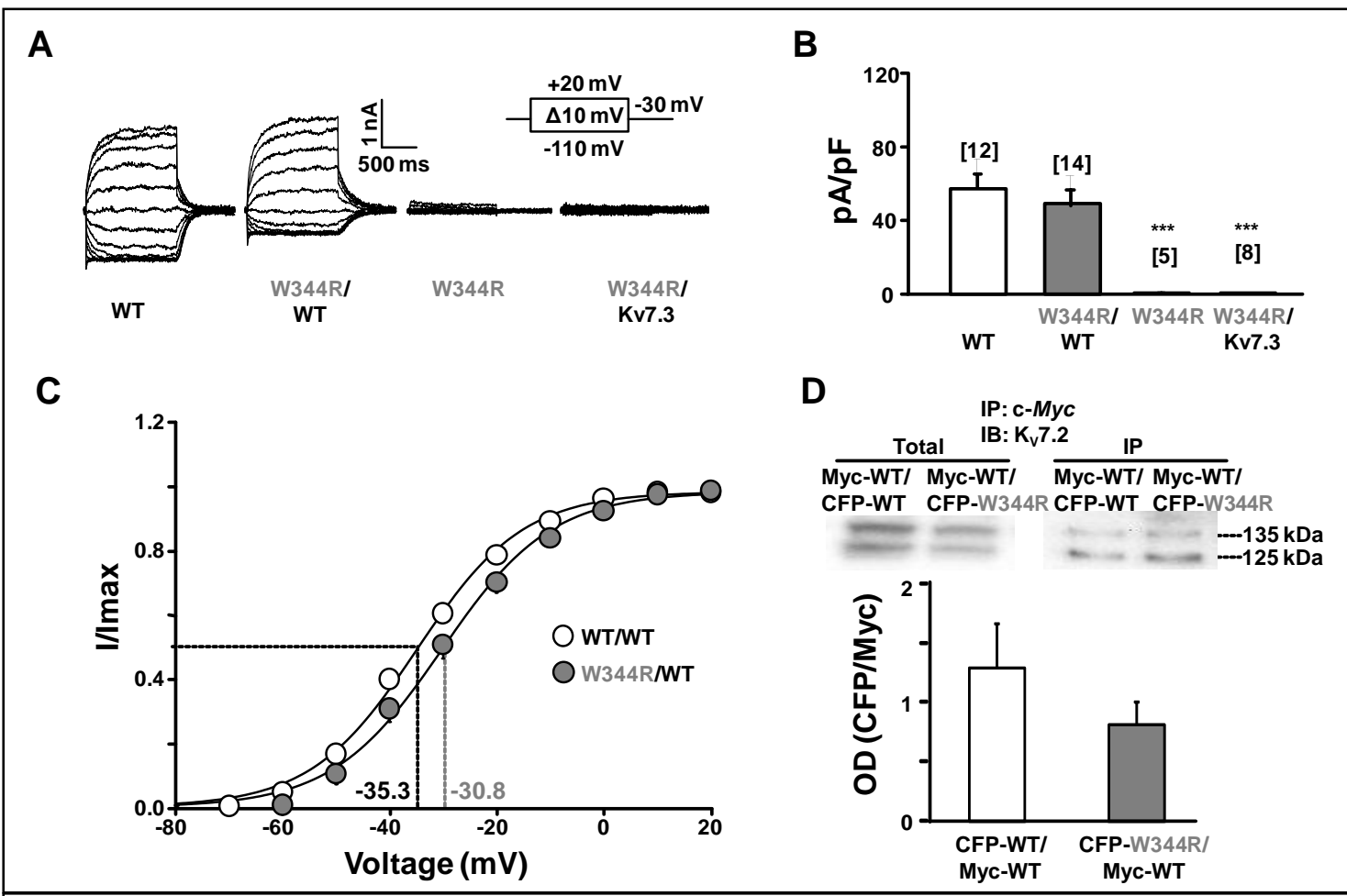

Figure 1. Functional consequences of the W344R mutation. A. Representative current traces evoked in cells expressing the indicated subunits. Inset: voltage protocol. B. Representation of the current density $(\mathrm{pA} / \mathrm{pF})$ from each group at $+20 \mathrm{mV}$ from tail currents. $\mathrm{K}_{\mathrm{v}} 7.2$ wild type homomers (WT, white) and heteromers (WT/W344R, gray) had $57.0 \pm 11.74$ $\mathrm{pA} / \mathrm{pF}$ and $49.0 \pm 8.51 \mathrm{pA} / \mathrm{pF}$, respectively. $\mathrm{K}_{\mathrm{v}} 7.2$ mutant $(\mathrm{W} 344 \mathrm{R})$ and $\mathrm{K}_{\mathrm{v}} 7.2-\mathrm{W} 344 \mathrm{R} / \mathrm{K}_{\mathrm{v}} 7.3$ heteromers produced negligible current. Number of cells is indicated in brackets. C. Currentvoltage relationship of $\mathrm{K}_{\mathrm{v}} 7.2 \mathrm{WT}$ homomers $\left(\mathrm{V}_{1 / 2}=-35.3 \pm 0.43 \mathrm{mV}, \mathrm{k}=10.5 ; \mathrm{n}=12\right)$ and WT/W344R heteromers $\left(\mathrm{V}_{1 / 2}=-30.8 \pm 0.64 \mathrm{mV}, \mathrm{k}=11.01 ; \mathrm{n}=14\right) .{ }^{* * *} \mathrm{p}<0.001$. D. Top: representative immunoblot revealed with anti-K 7.2 antibody before (left) and after (right) immunoprecipitating with anti-Myc antibody from cells expressing the indicated Myc-tagged Kv7.2 subunits $(\sim 125 \mathrm{kDa})$ and CFP-tagged Kv7.2 ( 135 kDa). Bottom: relative densitometry of the two bands. IP: immunoprecipitation, IB: immunobloting. $n=3$. 


\section{Co-translational misfolding in epilepsy}

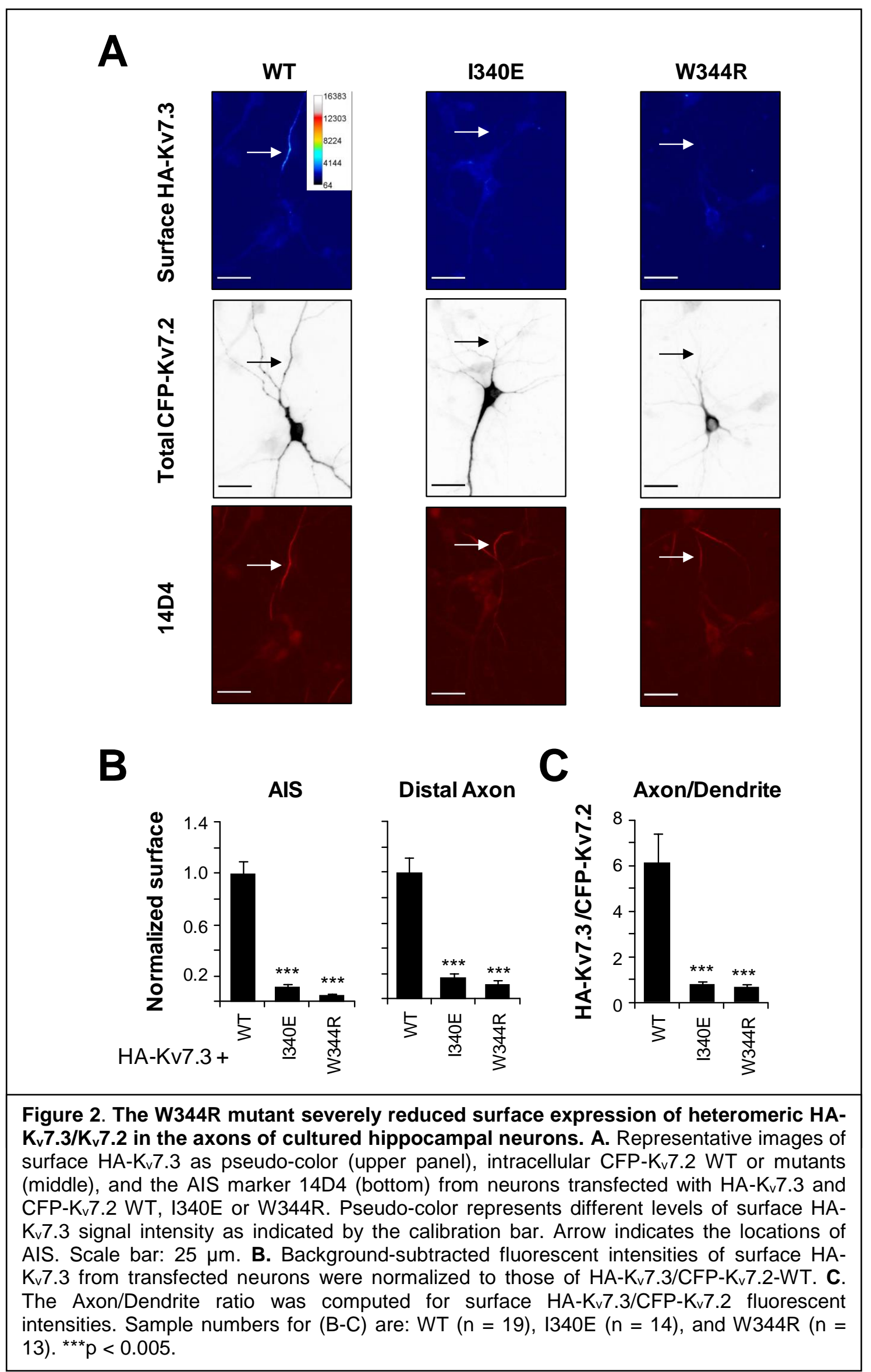




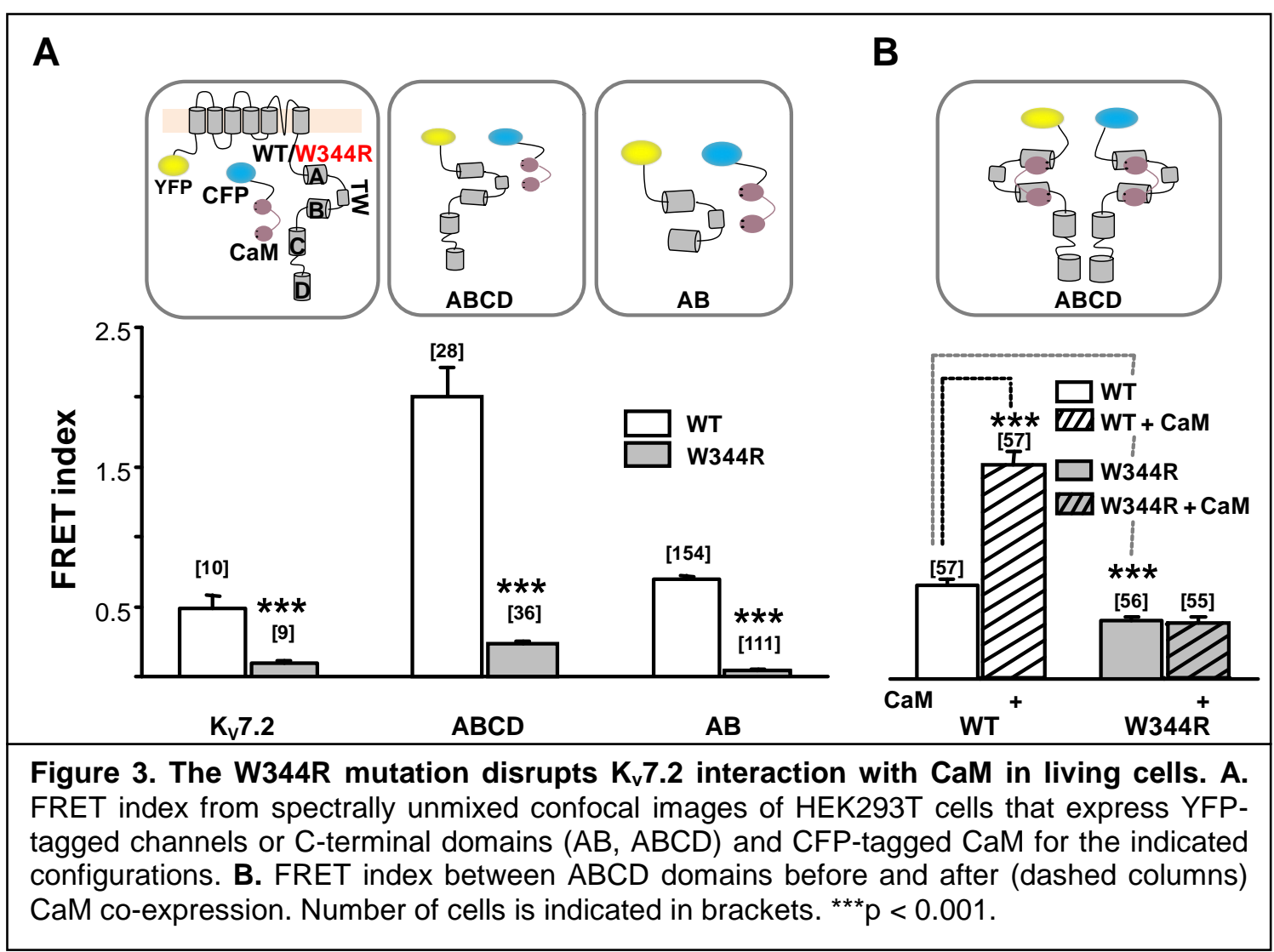


A

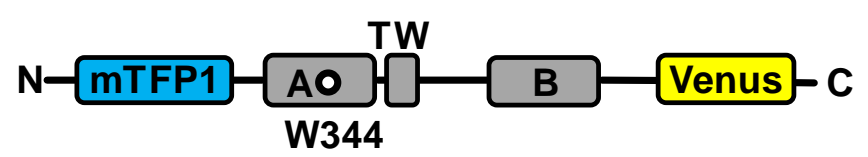

B
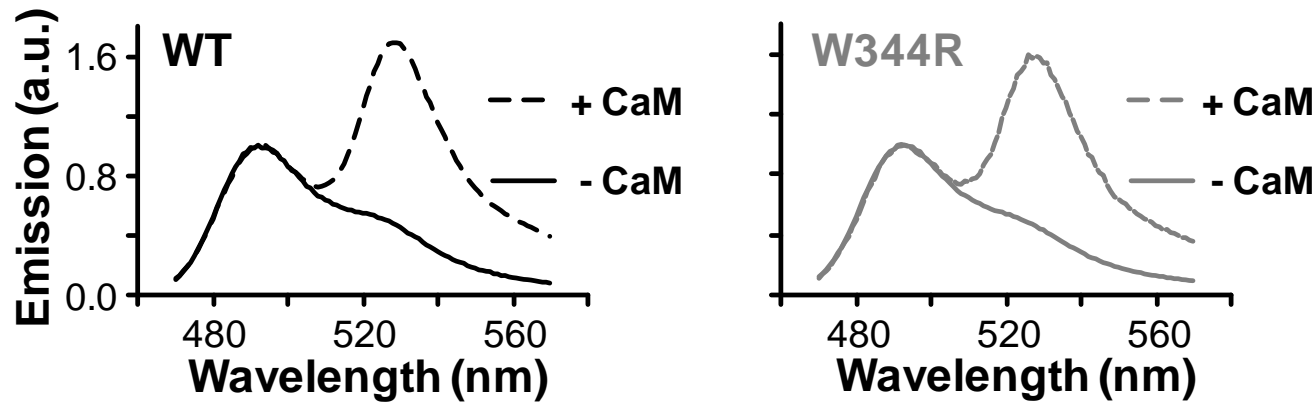

D
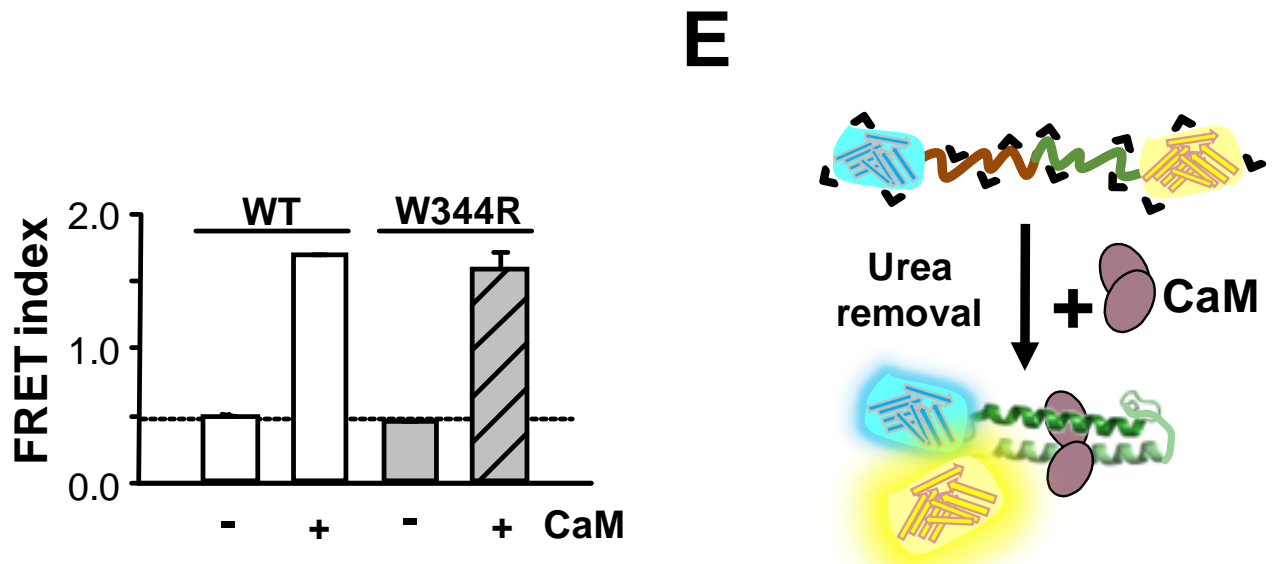

Figure 4. The W344R mutation is compatible with proper folding of the CRD. A. Schematic representation of the "folding biosensor". Helices A and B are flanked by mTFP1 and mcpVenus fluorescent proteins. Emission spectra of WT (B) and W344R (C) biosensors after denaturalization with $6 \mathrm{M}$ urea and subsequent dialysis without (solid lines) and with (dashed lines) CaM. D. FRET index values of WT (white) and W344R (gray) proteins from data as in B and C. The dotted horizontal line marks the index computed in the absence of acceptor. E. Schematic interpretation of the experiment: Upon refolding in the presence of $\mathrm{CaM}$, the fluorescent proteins are within FRET distance. 
A

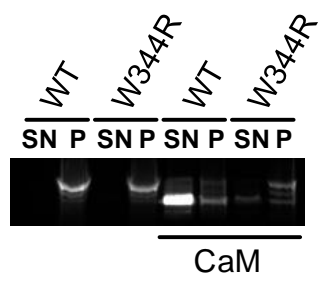

C

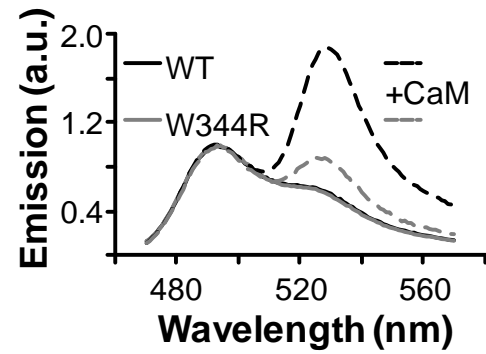

B

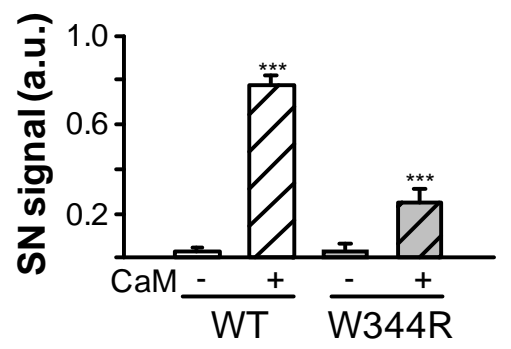

D

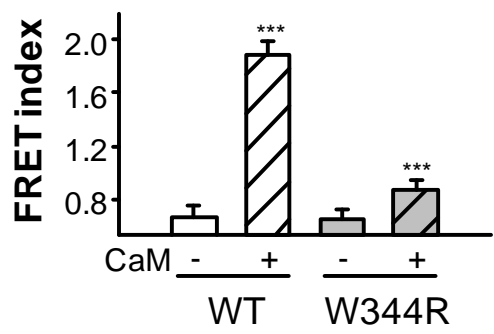

E
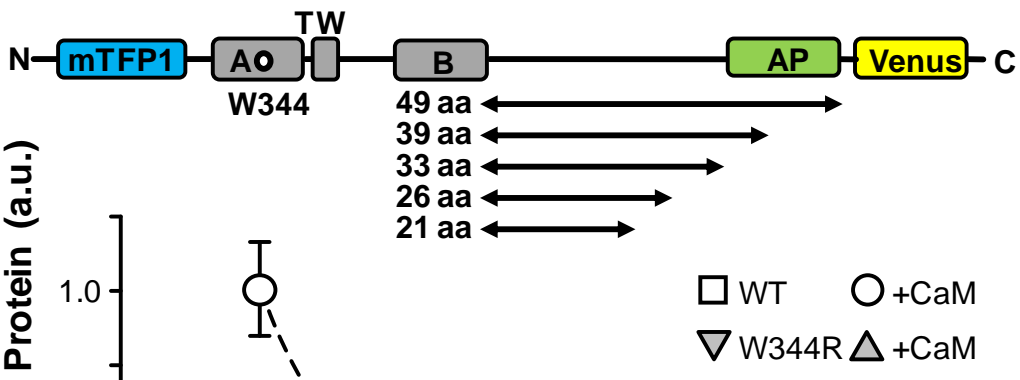

Figure 5. The W344R mutation disrupts folding of the CRD. A. Fluorescent image of a pseudo-native SDS-PAGE of bacterial extracts expressing WT or W344R biosensors at $37^{\circ} \mathrm{C}$. Proteins were co-expressed (right columns) or not (left columns) with CaM. Soluble (supernatant; SN) and insoluble (pellet; P) protein fractions were separated, and loaded as indicated. B. Fluorescence intensity of the supernatant band of SDS-PAGE gels $(n=3)$. C. Emission spectra of the soluble fraction of WT (black lines) and W344R (grey lines) proteins expressed alone (solid lines) or co-expressed with CaM (dashed lines). D. FRET index values from spectra as in C. E. Top. Schematic representation of the constructs used for in vivo cotranslation folding monitoring. The CRD was cloned upstream of the SecM arresting peptide (AP) sequence with tethers of increasing length, ranging from 21 to 49 amino acids from the C-terminal conserved Pro of the SecM AP where translational stalling takes place. mTFP1 and mcpVenus were fused to the $\mathrm{N}$ - and $\mathrm{C}$-terminus, respectively. Folding events of the protein domains inside or outside the ribosomal tunnel alleviate SecM stalling and leads to an increase in the ratio of peak emission mcpVenus/mTPF1. Bottom, cotranslational folding profiles of the indicated $A B$ CRD constructs, expressed with and without CaM $(n \geq 4)$. 


\section{Co-translational misfolding in epilepsy}

A

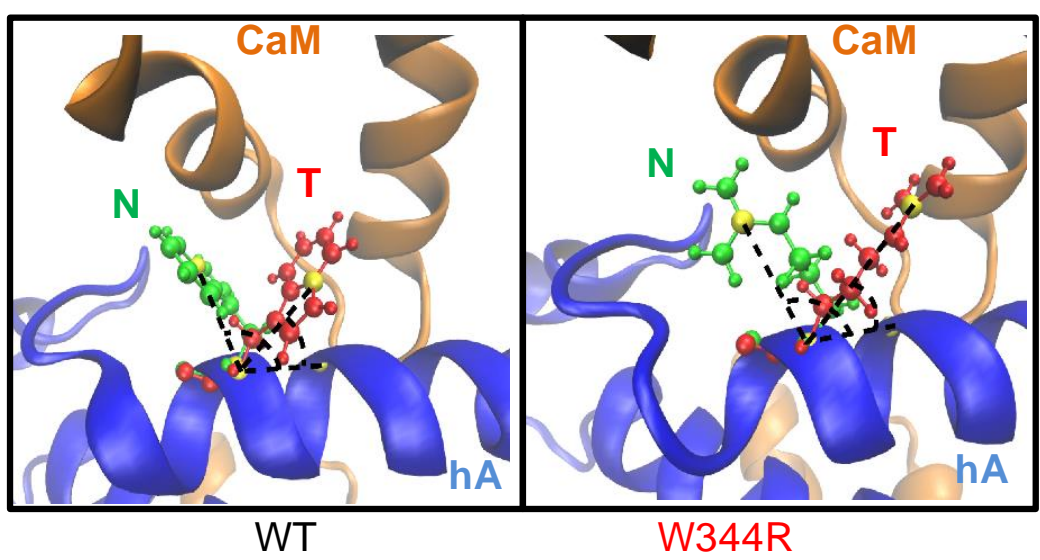

B

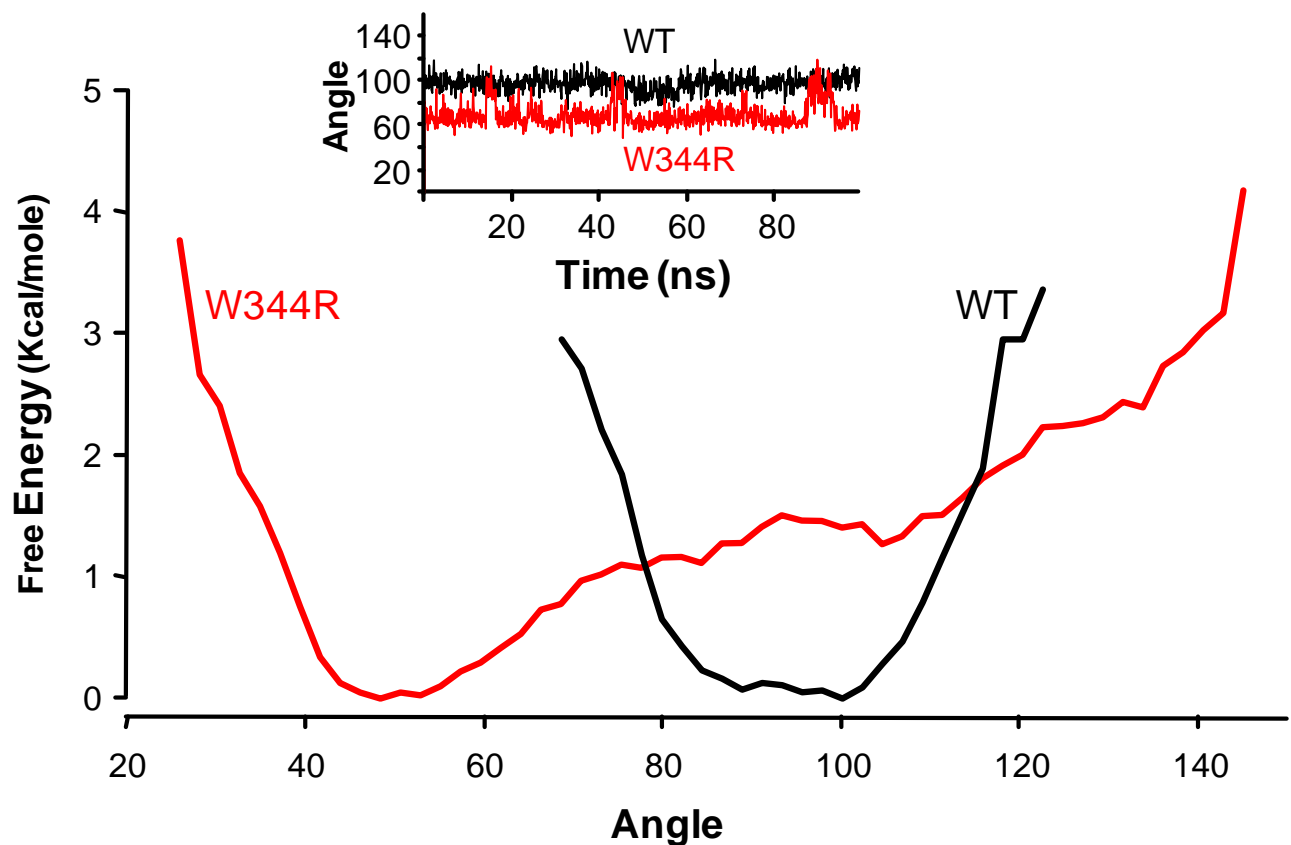

Figure 6. Two orientations for the lateral chain at position 344. A. Overlaid representation of both Tilted ( $T$, red) and Native-like ( $N$, green) structures of WT (left) and W344R mutant (right), where hA is blue whereas the CaM C-lobe is orange. Angles between $\mathrm{hA}$ and $\mathrm{T}$ or $\mathrm{N}$ structures are indicated. B. Projection of the free energy in the angles between hA and tryptophan or arginine at position 344. Note that the angles of the $\mathrm{N}$ and $\mathrm{T}$ orientations depend on the presence or absence of CaM. Due to the mathematical computations involved, as WT is not able to explore angles in the ranges $\left(20^{\circ}-65^{\circ}\right)$ and $\left(125^{\circ}-150^{\circ}\right)$, the resulting free energy would be infinite, and it is not showed. The inset shows the time series of the angle through the simulation (Supplemental Figure 9). 


\section{MATERIAL AND METHODS}

\section{CELL CULTURE AND TRANSFECTION}

Human Embryonic Kidney cells (HEK293T) were cultured in DMEM (Dubelcco's modified Eagle's medium), supplemented with $10 \%$ of fetal bovine serum, $1 \%$ noessential amino acids and $1 \%$ of gentamicin. Cell cultures were maintained in $5 \% \mathrm{CO}_{2}$ at $37^{\circ} \mathrm{C}$. Cells were transiently transfected with desired cDNAs using Polyethylenimine

473 (1 $\mu \mathrm{g} / \mathrm{\mu l}$; Polysciences) for electrophysiological studies, FRET and Co474 immunoprecipitation experiments.

\section{ELECTROPHYSIOLOGY}

The human isoform $3 \mathrm{~K}_{\mathrm{v}} 7.2$ (Y15065) and $\mathrm{K}_{\mathrm{v}} 7.3$ (NM004519) cDNA. The subunits were tagged at the N-terminus with mCFP or mYFP fluorescent proteins and cloned into pcDNA3.1, respectively were used in this study. N-terminal tags have no impact on the electrophysiological properties of the expressed channels $[7 ; 27]$. Macroscopic currents were recorded at room temperature $\left(22^{\circ} \mathrm{C}\right)$ in the whole-cell configurations of the patch-clamp technique using HEKA patch clamp EPC8. Borosilicate capillary glass (Sutter instrument) was pulled obtaining a tip resistance of 1-3 $\mathrm{M} \Omega$ after filled with the internal solution. This solution contains (in $\mathrm{mM}$ ): $125 \mathrm{KCl}, 10$ Hepes (K), $5 \mathrm{MgCl}_{2}, 5$ EGTA, $5 \mathrm{Na}_{2} \mathrm{ATP}$, adjusted to $\mathrm{pH} 7.2$ with $\mathrm{KOH}$ and the osmolarity adjusted to $\sim 300$ mOsm with mannitol.

Following patch rupture, whole-cell membrane capacitances were measured from integration of the capacitive transients elicited by voltage steps from -50 to -60 $\mathrm{mV}$, which did not activate any time dependent membrane current. Series resistances were compensated $80 \%$ in order to minimize voltage errors and were checked regularly throughout the experiment to ensure that there were no variations with time. The voltage-clamp experimental protocols were controlled with the "Clampex" program of the "pClamp" software (Molecular Devices). HEK293T cells were perfused with the external solution containing (in $\mathrm{mM}$ ): $140 \mathrm{NaCl}, 4 \mathrm{KCl}, 2 \mathrm{MgCl}_{2}\left(6 \mathrm{H}_{2} \mathrm{O}\right), 10$ Hepes-Na, $2 \mathrm{CaCl}_{2}$ and 5 glucose, $\mathrm{pH} 7.4$ with $\mathrm{NaOH}$ and the osmolarity adjusted to $\sim 320$ mOsm with mannitol.

The amplitude of the $\mathrm{K}_{\mathrm{v}} 7$ current was defined as the peak difference in current relaxation measured at $-30 \mathrm{mV}$ after $500-1,500 \mathrm{~ms}$ pulses to $-110 \mathrm{mV}$ (all channels closed) and to $+20 \mathrm{mV}$ (all channels opened). 
A confluent T-75 flask of HEK293T cells were co-transfected with $5 \mu \mathrm{g}$ of KCNQ2-WT cDNA in pcDNA3.1, N-terminally tagged with either CFP or Myc, and $5 \mu \mathrm{g}$ of CFP-KCNQ2-W344R cDNA for Co-Ip experiments to analyze protein-protein interaction. Twenty four hours after transfection, HEK293T cells were solubilized for 30 min at $4^{\circ} \mathrm{C}$ in RIPA buffer, containing (mM): 20 Tris- $\mathrm{HCl}(\mathrm{pH} 7.5), 150 \mathrm{NaCl}, 5$ EDTA, $1 \%$ NP40 and protease inhibitors (1X Complete; Roche Applied Science). The lysate was centrifuged at $800 \mathrm{~g}$ for $15 \mathrm{~min}$ and the insoluble material was removed after centrifugation at $13,000 \mathrm{~g}$ for $15 \mathrm{~min}$, after which the lysate was pre-cleared for $1 \mathrm{~h}$ at 4 ${ }^{\circ} \mathrm{C}$ with $40 \mu \mathrm{l}$ of equilibrated protein G-Sepharose beads (GE Healthcare). The day before, anti-c-Myc (Sigma-Aldrich) antibody was immobilized overnight at $4^{\circ} \mathrm{C}$ with 40 $\mu \mathrm{l}$ of equilibrated protein G-Sepharose beads and washed six times with RIPA buffer. 6-8 washes with RIPA buffer, the immunoprecipitated proteins were released by heating at $90^{\circ} \mathrm{C} 5 \mathrm{~min}$ in SDS sample buffer and were probed with anti $\mathrm{K}_{\mathrm{v}} 7.2$ antibody.

Immunoprecipitation samples were fractionated on $6 \%$ or $15 \%$ SDSpolyacrylamide gels and transferred to polyvinylidene fluoride membranes (PVDF) (Millipore). Membranes were blocked in TBS solution $(0.05 \%$ Tween-20 in PBS containing $5 \%$ milk). Then, they were incubated with the monoclonal primary antibody: anti-K $K_{v} 7.2$ (1:1,000; Neuromab). Secondary antibody was goat anti-mouse IgG horseradish peroxidase conjugate (1:5,000; Bio-Rad). Blots were developed using the Luminata Forte Western HRP substrate reagent (Millipore) and images were digitalized with a Thermo Scientific MYECL Imager. Densitometry of the bands was measured by FIJI software. It was calculated dividing co-immunoprecipitated protein by immunoprecipitated protein, i. e. CFP-K $7.2 / \mathrm{c}-\mathrm{Myc}_{\mathrm{c}} \mathrm{K}_{\mathrm{v}} 7.2$.

Cells were plated at $\sim 60 \%$ confluence onto $30-\mathrm{mm}$ round coverslips in six-well plates. Cells were transfected as described above. For CFP-CaM binding to YFP-

$528 \mathrm{~K}_{\mathrm{v}} 7.2$, YFP-ABCD or YFP-AB the transfection ratio used was 1:5 with a total of $0.6 \mu \mathrm{g}$ 529 DNA per M35 dish. For assembly experiments, the ratio was 1:1:2 (0.5 $\mu \mathrm{g}$ of each 530 FCP-tagged ABCD and $1 \mu \mathrm{g}$ of CaM or $1 \mu \mathrm{g}$ of empty pcDNA3.1 his/c-Myc vector). 531 Twenty-four hours after transfection, coverslips were placed in an imaging chamber 532 and imaged maintaining them in buffer solution composed of $(\mathrm{mM}): 140 \mathrm{NaCl}, 5 \mathrm{KCl}, 1$ $533 \mathrm{MgCl}_{2}, 2 \mathrm{CaCl}_{2}, 10$ glucose and $10 \mathrm{Na}$-Hepes, $\mathrm{pH} 7.4$ at room temperature. 

microscope (Nikon Instruments, Tokyo, Japan) equipped with a confocal scanning head and a spectral detector module. Images were captured using a 60X oil objective, with the pinhole opened $(150 \mu \mathrm{m})$ and using the $405 \mathrm{~nm}$ laser line (Coherent, Santa Clara, CA, USA) or the $488 \mathrm{~nm}$ line (Melles-Griot, Rochester, NY, USA) for direct CFP or YFP excitation, respectively. To assure homogeneity in donor an acceptor expression, cells displaying a signal with emission values between 20 and 170 (arbitrary units) when excited at $405 \mathrm{~nm}$ (to record FRET signal) and when excited at $488 \mathrm{~nm}$ (to record acceptor emission only) were included in the analysis with FIJI.

The spectral detector allows simultaneous recording of 32 images, each registering a $5 \mathrm{~nm}$ band of the spectrum, covering 450-610 $\mathrm{nm}$. After spectral unmixing with EZ-C1 Nikon software, using cells expressing CFP or YFP alone as reference, as described previously [34], the area under the spectra was measured and a FRET index was calculated as FRET index $=\mathrm{YFP}_{405} / \mathrm{CFP}_{405}$, where YFP is the integral of emission signal for $\mathrm{YPP}_{405}$, and $\mathrm{CFP}_{405}$ is the integral of the emission signal for CFP after excitation with the $405 \mathrm{~nm}$ laser line.

All procedures involving animals were reviewed and approved by the Institutional Animal Care and Use Committee at the University of Illinois UrbanaChampaign in accordance with the guidelines of the U.S National Institutes of Health (Protocols 15222). Primary dissociated hippocampal cultures were prepared from 18day old embryonic rats and transfected with plasmids (total $0.8 \mu \mathrm{g}$ ) at 5 DIV as described [32].

\section{IMMUNOCYTOCHEMISTRY}

Primary dissociated hippocampal cultures were prepared from 18-day old embryonic rats, transfected with plasmids (total $0.8 \mu \mathrm{g}$ ) at 5 DIV, and immunostaining for surface and total $K_{v} 7$ subunits and Axonal Initial Segment (AIS) markers in hippocampal neurons were performed at $48 \mathrm{~h}$ post transfection as described [32]. Fluorescence images were acquired as described [5; 32] using a Zeiss Axio Observed inverted microscope equipped with a Zeiss AxioCam 702 mono Camera and ZEN Blue 2.6 software, and stored with no further modification as CZI and 16-bit TIFF files. Within one experiment, the images were acquired using the same exposure time to compare the fluorescence intensity of the neurons transfected with different constructs. 
569 from the beginning of the axon (distal axon), and the major primary dendrites were quantified using ImageJ Software (National Institutes of Health) as described [32]. by mTFP1 and mcpVenus fluorophores in the $\mathrm{N}$ - and $\mathrm{C}$ - termini respectively were transformed in E. coli BL21 cells alone or together with the pOKD4 plasmid carrying the CaM gene. Cells were grown over night at $37^{\circ} \mathrm{C}$ and diluted into $20 \mathrm{ml}$ of fresh LB for further growing at $37^{\circ} \mathrm{C}$ till $\mathrm{OD}_{600}$ 0.6. Protein expression was induced during $3 \mathrm{~h}$ at $37^{\circ} \mathrm{C}$ or overnight at $18^{\circ} \mathrm{C}$ by addition of $1 \mathrm{mM}$ IPTG. Cells were harvested by centrifugation at $7,000 \mathrm{rpm}$ for $10 \mathrm{~min}$. The cell pellets were resuspended in lysis buffer $50 \mathrm{mM}$ Hepes, pH 7.4, $120 \mathrm{mM} \mathrm{KCl,} 5 \mathrm{mM} \mathrm{NaCl}, 5 \mathrm{mM}$ EGTA, $1 \mathrm{mM}$ DTT and protease inhibitors (1X Complete; Roche Applied Science), and similar OD values were fitted for all the samples. The cellular cultures were sonicated 3 times, $5 \mathrm{~s}$ ON, $5 \mathrm{~s}$ OFF and centrifuged at $19,000 \times \mathrm{g}$ during $30 \mathrm{~min}$ for supernatant and pellet separation. The pellets were resuspended in the same buffer volume used before. Protein solubility was studied by SDS-PAGE electrophoresis (10\%), by analyzing the protein amount present in the same volume of pellet and supernatant fractions. The gels were visualized using Versadoc imaging equipment, exciting using blue or green leds, combined with 530BP28 or 605BP35 emission filters. The protein amount in the pellet and in the supernatant was estimated relative to the total protein amount by quantification of the gel bands using the ImageJ software. The protein soluble fractions were also analyzed in a Fluoromax-3 fluorimeter by recording the emission spectra of mTFP1 and mcpVenus fluorescent proteins upon excitation at 458 and $515 \mathrm{~nm}$ respectively.

UREA MEDIATED

PROTEIN

DENATURALIZATION

AND RENATURALIZATION

$\mathrm{K}_{\mathrm{v}}$ 7.2 WT and W344R cloned in pProHex-HTc were transformed in E. coli BL21 cells in the absence of $\mathrm{CaM}$ and grown over night at $37^{\circ} \mathrm{C}$. Cell cultures were diluted into $20 \mathrm{ml}$ of fresh LB for further growing at $37^{\circ} \mathrm{C}$ till $\mathrm{OD}_{600} 0.6$. Protein expression was induced during $3 \mathrm{~h}$ at $37^{\circ} \mathrm{C}$ by addition of $1 \mathrm{mM}$ IPTG. Cells were harvested by centrifugation at 7,000 rpm for $10 \mathrm{~min}$ and resuspended in $500 \mu$ lysis buffer $120 \mathrm{mM}$ $\mathrm{KCl}, 50 \mathrm{mM}$ Hepes, $\mathrm{pH}$ 7.4, $1 \mathrm{mM}$ PMSF, 1\% Triton and protease inhibitors. The cellular cultures were sonicated 3 times, 5 s ON, 5 s OFF and centrifuged at 19,000 x g during 30 minutes for supernatant and pellet separation. The pellets were resuspended

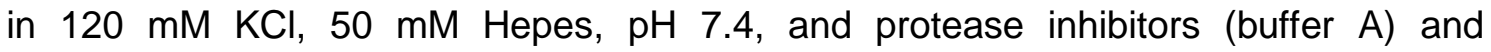


supplemented with $1 \mathrm{M}$ urea and incubated for 20 minutes. Samples were centrifuged again at 19,000 $\mathrm{g}$ g for 30 minutes and resuspended in buffer $\mathrm{A}$ containing $6 \mathrm{M}$ urea for protein extraction. After 30 minutes incubation at $4^{\circ} \mathrm{C}$, the solubilized proteins were collected by centrifugation at $19,000 \times \mathrm{g}$ during $30 \mathrm{~min}$ and diluted to $0.1 \mathrm{mg} / \mathrm{ml}$. Diluted proteins were dialyzed in the absence and presence of CaM against buffer $120 \mathrm{mM}$ $\mathrm{KCl}, 50 \mathrm{mM}$ Hepes, $\mathrm{pH}$ 7.4, $5 \mathrm{mM}$ DTT and urea decreasing concentrations. Proteins were finally dialyzed in $120 \mathrm{mM} \mathrm{KCl}, 50 \mathrm{mM}$ Hepes, $\mathrm{pH}$ 7.4, $5 \mathrm{mM} \mathrm{NaCl}, 5 \mathrm{mM}$ EGTA and $5 \mathrm{mM}$ DTT for further fluorescence recordings.

\section{ARRESTING PEPTIDE EXPERIMENTS}

The sequence coding for the SecM arresting peptide (AP) FSTPVWISQHAPIRGSP was inserted between helix $B$ and mcpVenus into the DNAs cloned in pProHex-HTc corresponding to WT and W344R CRD flanked by mTFP1 and mcpVenus fluorophores in the $\mathrm{N}$ - and $\mathrm{C}$-termini respectively. The sequence (EFYVGYVPGGSPGRPGGSRPHVGSGGQQGSHV) of the linker joining helix $B$ with SecM AP contained restrictions sites that allowed creating a library with 21, 26, 33, 39 and 49 amino acids. The constructs were transformed in E. coli BL21 cells alone or together with the pOKD4 plasmid carrying the CaM gene. Single colonies were used to start overnight cultures, which were induced and processed as described in translation analysis. The protein soluble fractions were also analyzed in a Fluoromax-3 fluorimeter by recording the emission spectra of mTFP1 and mcpVenus fluorescent proteins upon excitation at 458 and $515 \mathrm{~nm}$ respectively.

\section{STABILITY CALCULATIONS}

Binding affinities have been computed for five different mutations at position 344 using the Rosetta Flex $d d G$ [47] prediction protocol for the $\mathrm{CaM} / \mathrm{K}_{\mathrm{v}} 7.2-\mathrm{hAB}$ complex (PDB: 6FEG [15]). In short, WT and mutant models are generated by performing random displacements of the protein backbone named "backrub moves" in a shell of $8 \AA$ around the mutation site. Side chains of both WT and mutants are optimized by assigning a score to each mutation, based on the all atom Rosetta Energy Function 2015 [48]. The resulting score associated to the mutation is compared with the WT to compute $\Delta \Delta G=\Delta G_{\text {Mutation }}-\Delta G_{W T}$. Therefore, if $\Delta \Delta G>0$ the WT would show a stronger binding affinity compared to the mutated one, and the opposite for $\Delta \Delta G<0$. Following Rosetta's protocol, fifty different simulations were performed for each mutant, and each one consists of 50,000 backrub moves. These random moves are accepted or rejected based on the Metropolis criterion with an energy of $1.2 \mathrm{kT}$, and the final value of the binding affinity is the mean value of all 50 simulations. The backrub moves 
constitute a random trajectory in the angles and provides a sampling of possible configurations of the residue 344 side chain. For each move the free energy difference $(\Delta G)$ is calculated considering the Rosetta energy function 2015 and its final value is the mean value of all 50 simulations.

Additionally, as atomic coordinates are saved every 5,000 steps and each simulation generates 10 snapshots of the trajectory, we used the VMD interface together with the CHARMM36 all-atom force field [61] to analyze in detail the structural characteristics of the simulations.

Finally, molecular dynamics simulations were carried out of the WT and mutant helices A, TW and B with the software NAMD 2.13 and the CHARMM36 all-atom force field. The input structure was PDB 6FEG [15] eliminating the $\mathrm{N}$-terminal residual amino acids up to residue number 328 . The simulation was performed in a periodic cubic box of TIP3P water so that the minimum distance of any protein atom and the edge of the box was at least $6.1 \AA$. A concentration of $120 \mathrm{mM}$ of $\mathrm{KCl}$ and $5 \mathrm{mM}$ of $\mathrm{NaCl}$ was introduced to mimic neuron physiology. SHAKE bond length constraints were applied to all bonds, nonbonded interactions were calculated by the particle-mesh Ewald method with a cutoff of $12 \AA$. The simulation was first minimized using 1,000 steepest descent steps, after that, $0.5 \mathrm{~ns}$ were simulated in the canonical ensemble at $298 \mathrm{~K}$, keeping the same temperature using Langevin dynamics with a Langevin damping of $0.5 \mathrm{ps}^{-1}$. After that, $1.5 \mathrm{~ns}$ of NPT ensemble was simulated in order to accommodate the periodic cell and avoid the formation of vacuum bubbles in the solvent with a pressure target of 1 atmosphere. Finally, 100 ns were simulated in NPT ensemble for both WT and W344R mutant systems.

STATISTICAL ANALYSIS

Values are presented as the mean \pm SEM. The differences between the means were evaluated using the unpaired Student's t-test or ANOVA with Mann-Whitney post hoc on SigmaStat Statistic (Sigmaplot 11), where values of $p<0.05$ were considered significant. The number of cells in each experiment is indicated in brackets in the figures. The results are from two or more independent batches of cells. In all figures *, ${ }^{* *}$, and ${ }^{* * *}$ indicate significance at $p<0.05, p<0.01$, and $p<0.001$, respectively.

Images from hippocampal neurons were analyzed using Origin 9.1 (Origin Lab), the Student's t-test and one-way ANOVA with post-ANOVA Tukey's and Fisher's multiple comparison tests were performed to identify the statistically significant difference with a priori value $p<0.05$ between two groups and for $>$ three groups, respectively. 


\section{Co-translational misfolding in epilepsy}

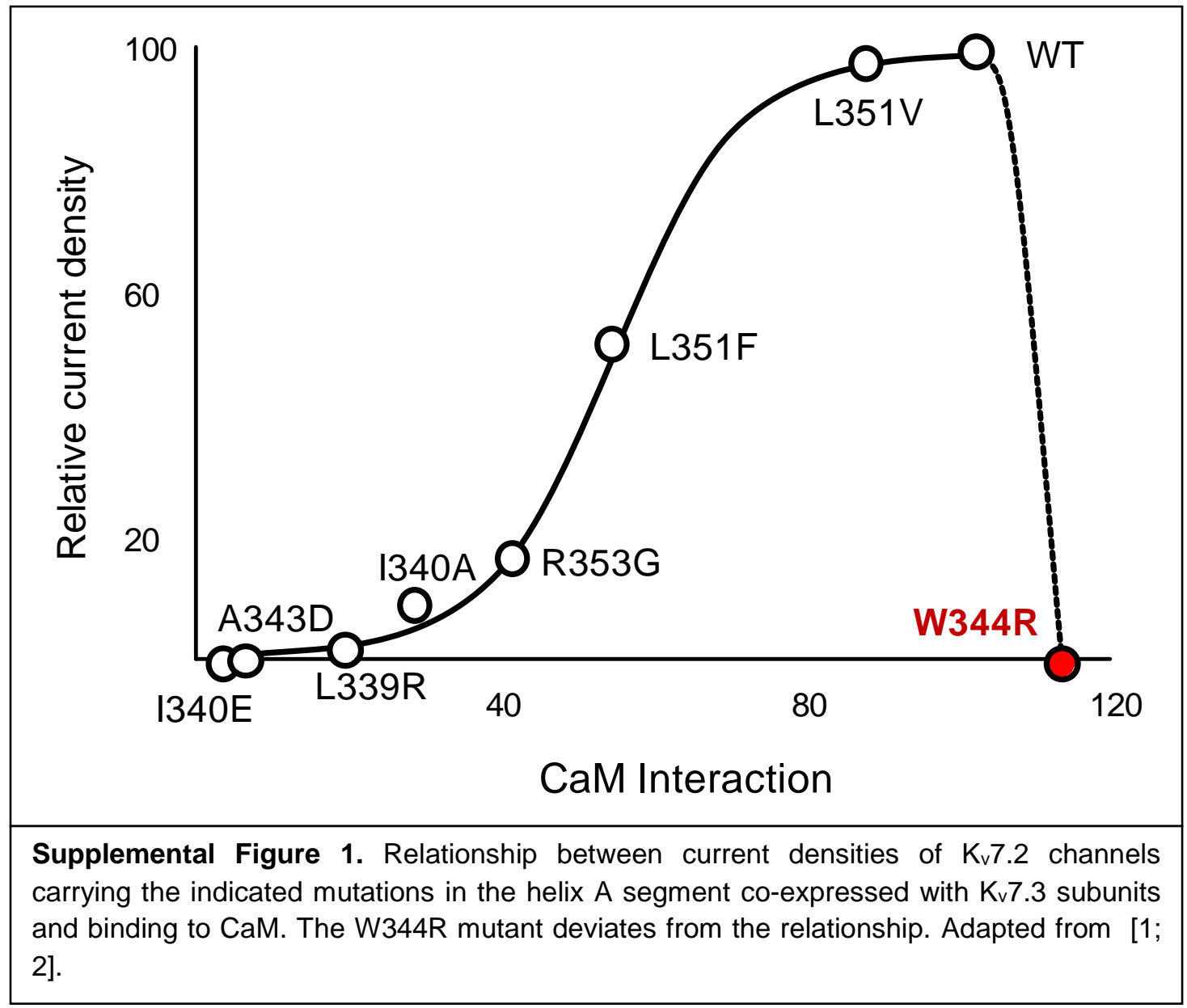

678 
Co-translational misfolding in epilepsy

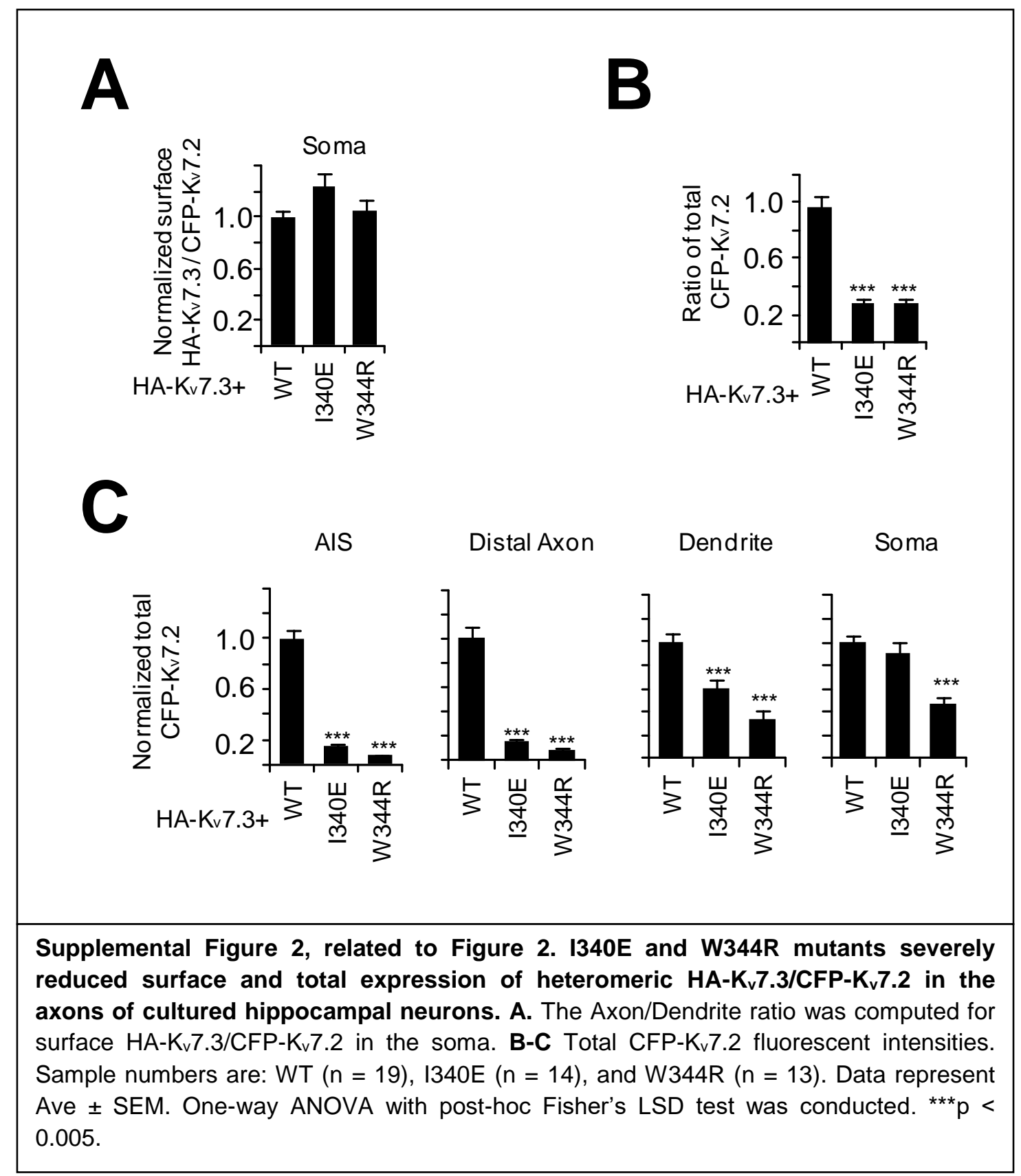




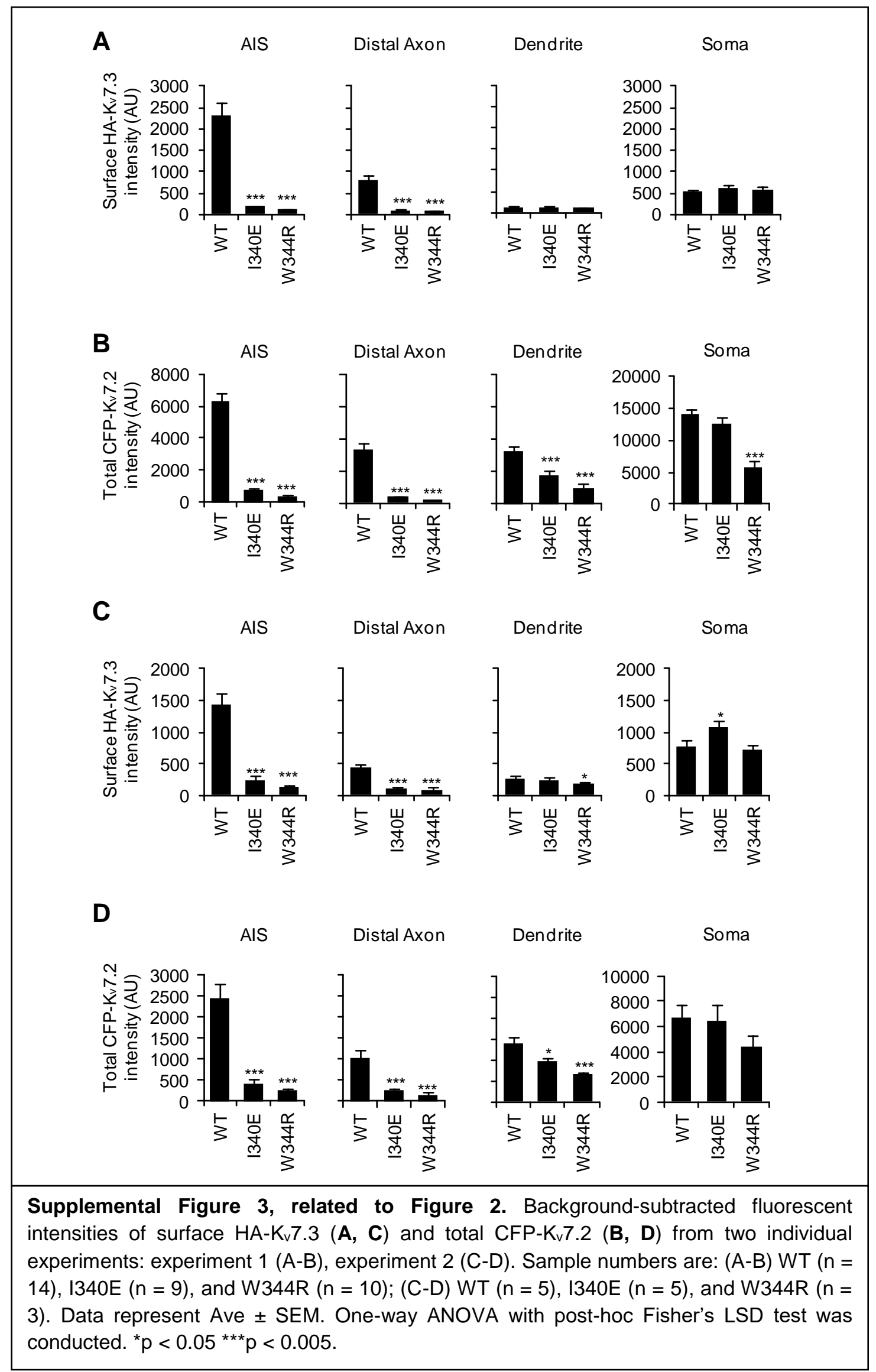




\section{Co-translational misfolding in epilepsy}

A

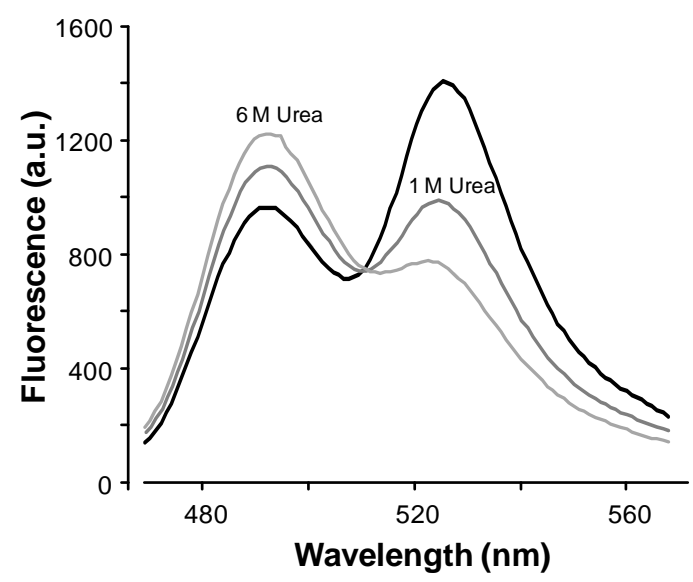

B

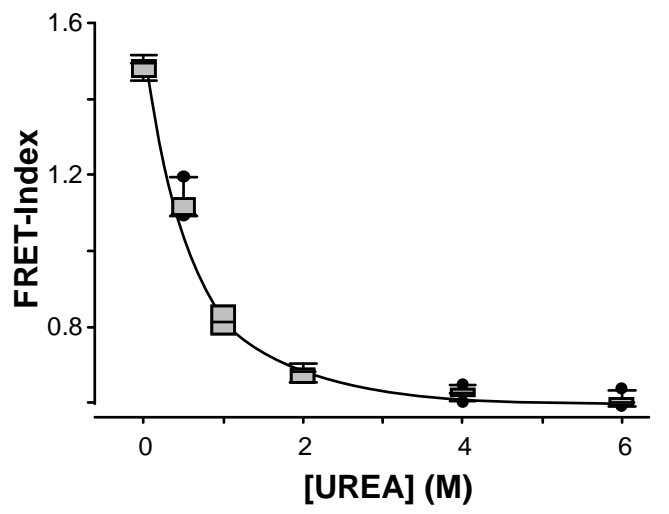

Supplemental Figure 4, related to Figure 4. A. Emission spectra of the purified mTFP1AB-mcpVenus/CaM complex in the presence of increasing concentrations of the denaturant urea. B. FRET index values expressed as the ratio mcpVenus/mTFP1 peak emission $(528 / 492 \mathrm{~nm})$ ratio from spectra as a function of urea concentration. 


\section{Co-translational misfolding in epilepsy}

A

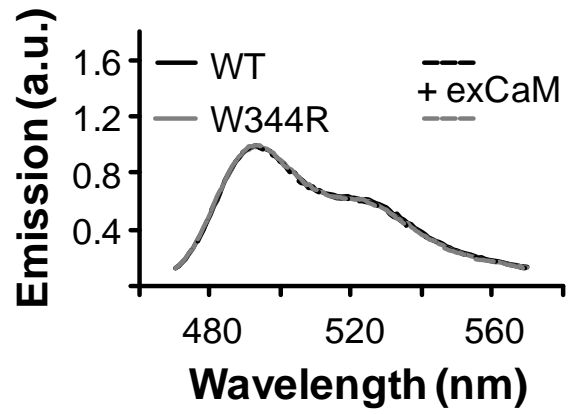

B

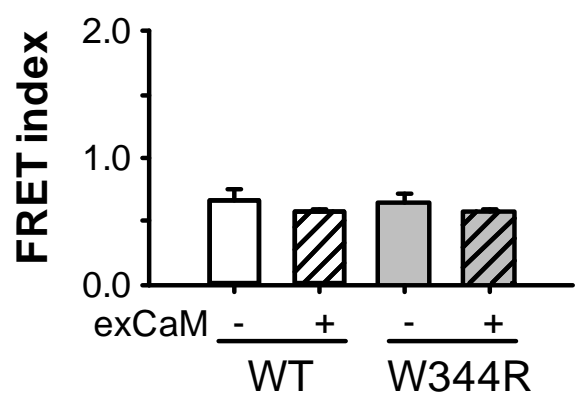

Supplemental Figure 5, related to Figure 5. A. Emission spectra of the soluble WT (black lines) and W344R (grey lines) proteins at $\sim 6 \mu \mathrm{M}$ translated in CaM-free nondenaturing conditions. An excess $(100 \mu \mathrm{M})$ exogenous-CaM (exCaM) was added to each sample (dotted lines) and the emission spectra were measured after 24 hours. B. FRET index values expressed as the ratio mcpVenus/mTFP1 peak emission $(528 / 492 \mathrm{~nm})$ from spectra as in A. 


\section{Co-translational misfolding in epilepsy}

A
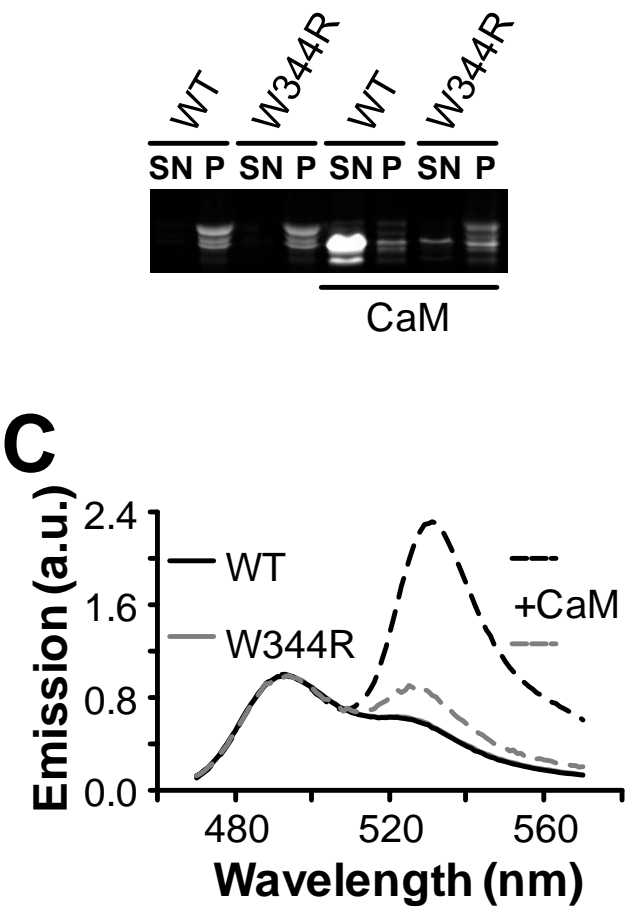

B

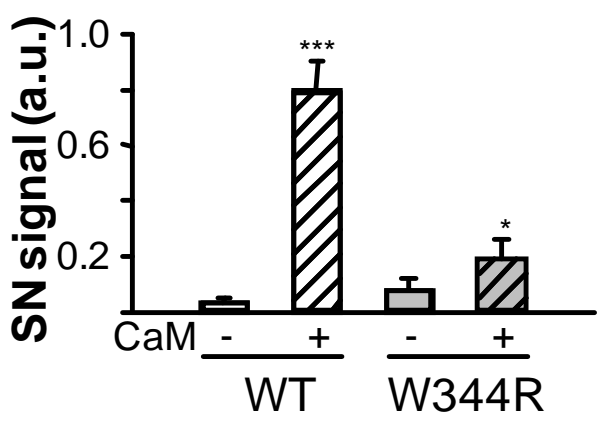

D

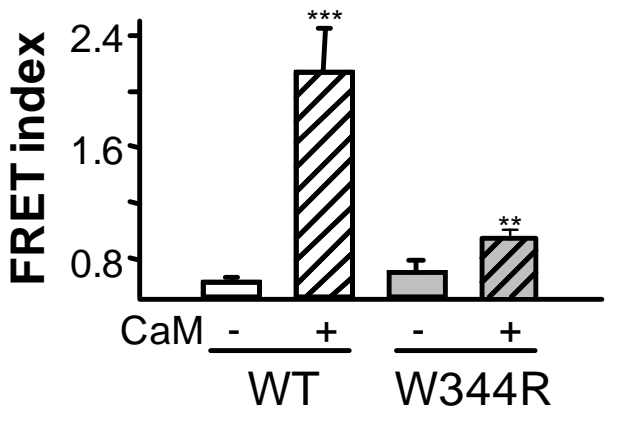

Supplemental Figure 6, related to Figure 5. A. Fluorescent image of a pseudo-native SDS-PAGE of bacterial extracts of cells expressing WT or W344R biosensors, expressed at $18^{\circ} \mathrm{C}$. Proteins were co-expressed (right columns) or not (left columns) with CaM. Soluble (supernatant; SN) and insoluble (pellet; P) protein fractions were separated, and loaded as indicated. B. Fluorescence intensity of the supernatant band of SDS-PAGE gel $(n=3)$. C. Emission spectra of the soluble fraction of WT (black lines) and W344R (grey lines) proteins expressed alone (solid lines) or co-expressed with CaM (dashed lines). D. FRET index values expressed as the ratio YFP/CFP peak emission (528/492 nm) ratio from spectra as in $\mathrm{C}$. 


\section{Co-translational misfolding in epilepsy}

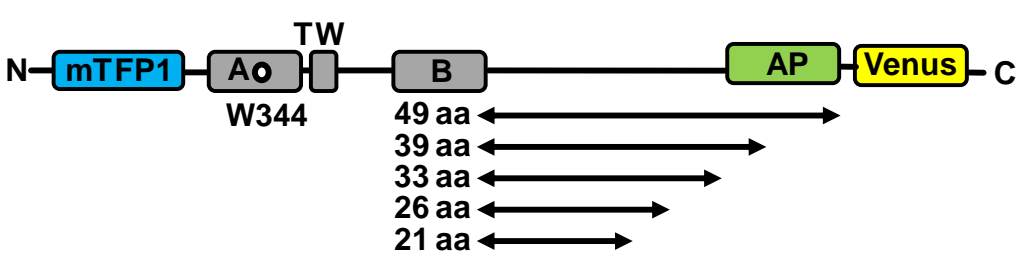

B
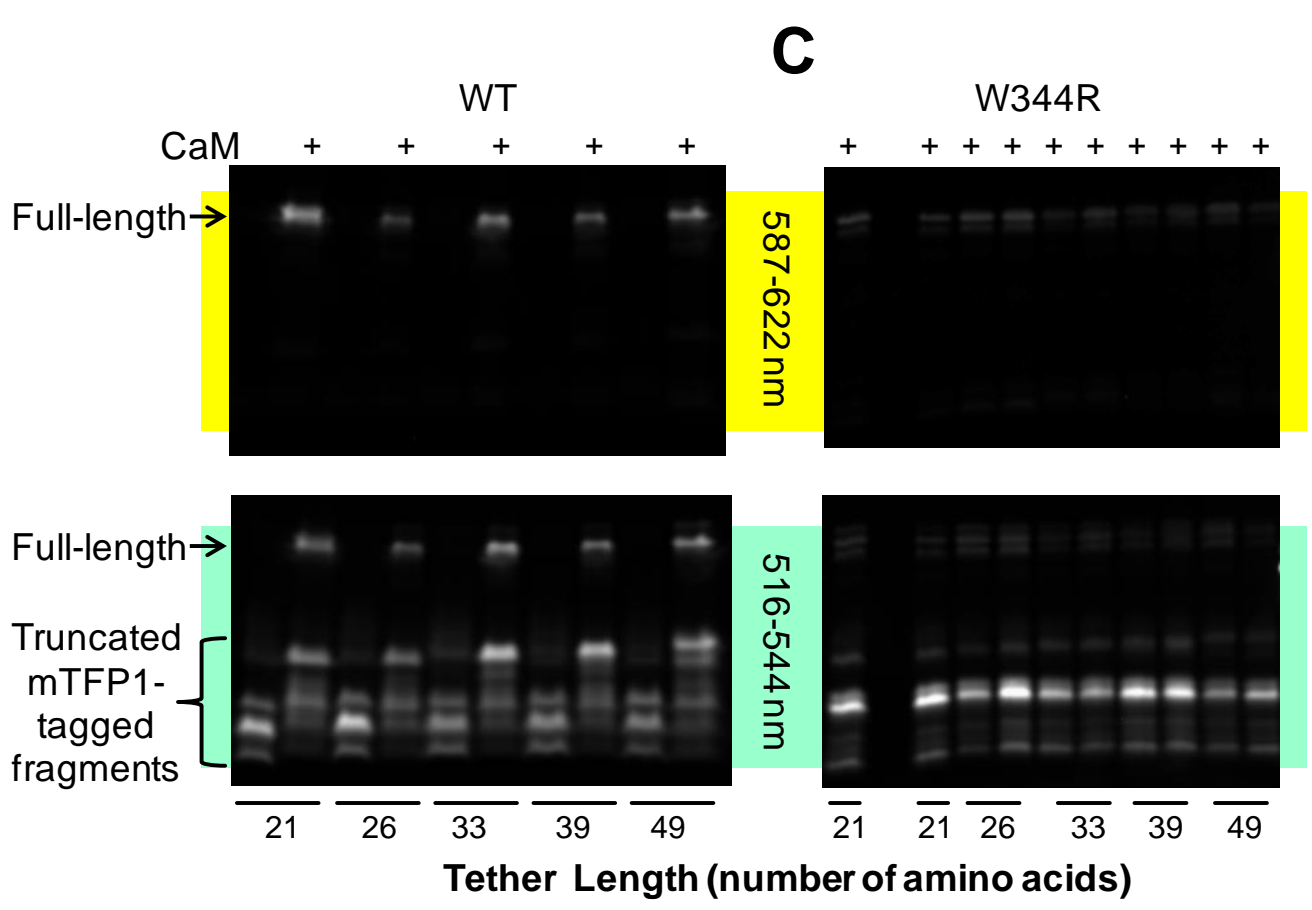

Supplemental Figure 7, related to Figure 5. A. Schematic representation of the constructs used for in vivo translation. The CRD was cloned upstream of the SecM arresting peptide (AP) sequence with tethers of increasing length, ranging from 21 to 49 amino acids from the C-terminal conserved Pro of the SecM AP where translational stalling takes place. B. Fluorescent images of a pseudo-native SDS-PAGE of bacterial extracts expressing WT-AP construct with and without $\mathrm{CaM}$, with tether lengths indicated at the bottom. A 605BP35 filter was used to isolate emission from mcpVenus on the image at the top, whereas the image at the bottom, a 530BP28 filter was used to detect emission from both mTFP1 and mcpVenus. C. Fluorescent images as in B of bacterial extracts expressing W344R-AP constructs in the presence of CaM. The second line was not loaded. 
bioRxiv preprint doi: https://doi.org/10.1101/2020.11.25.398222; this version posted November 26, 2020. The copyright holder for this preprint (which was not certified by peer review) is the author/funder, who has granted bioRxiv a license to display the preprint in perpetuity. It is made available under aCC-BY-ND 4.0 International license.

Co-translational misfolding in epilepsy

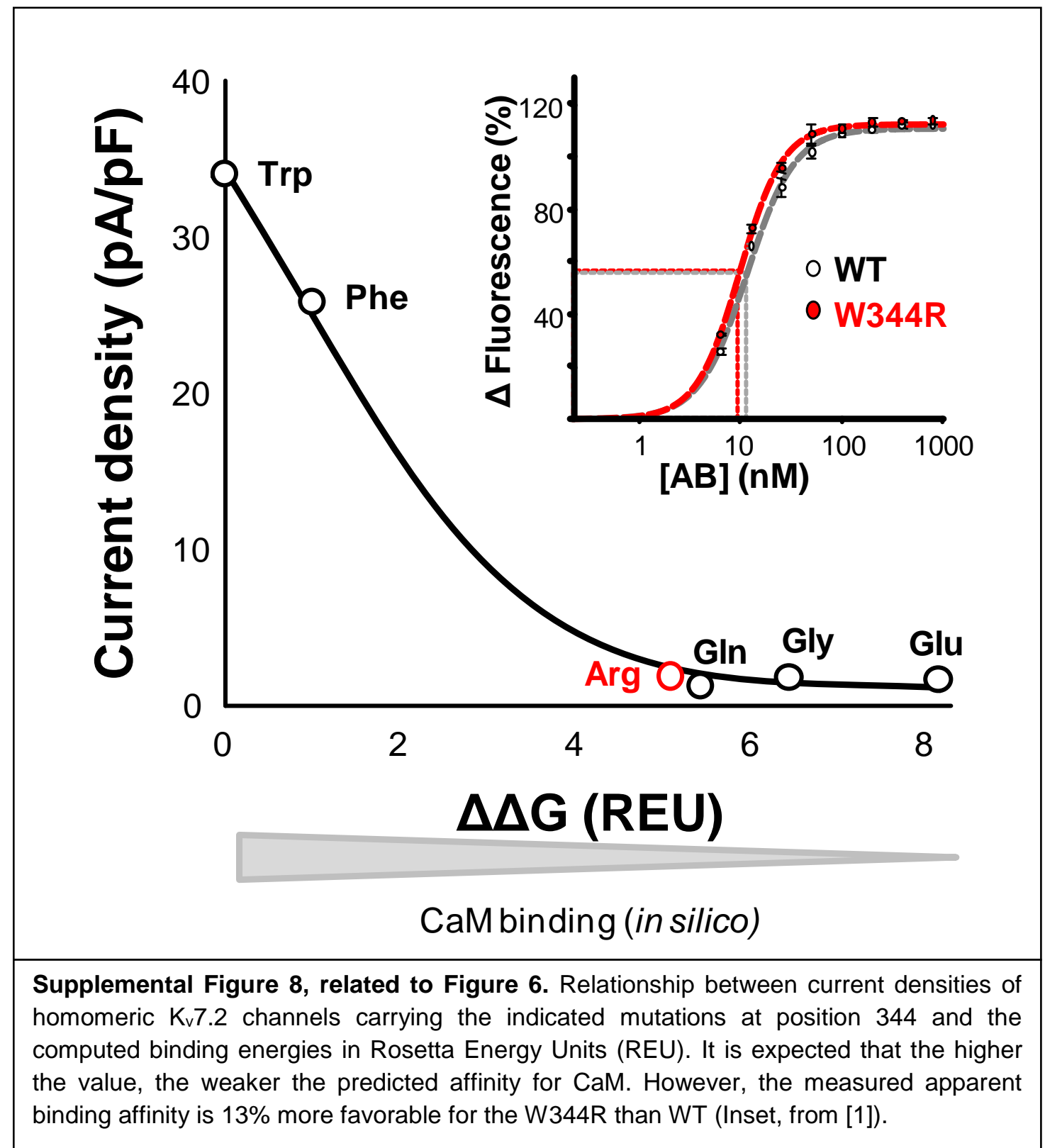


bioRxiv preprint doi: https://doi org/10.1101/2020.1125.398222; this version posted November 26,2020 . The copyright holder for this preprint (which was not certified by peer review) is the author/funder, who has granted bioRxiv a license to display the preprint in perpetuity. It is made available under aCC-BY-ND 4.0 International license.

\section{Co-translational misfolding in epilepsy}

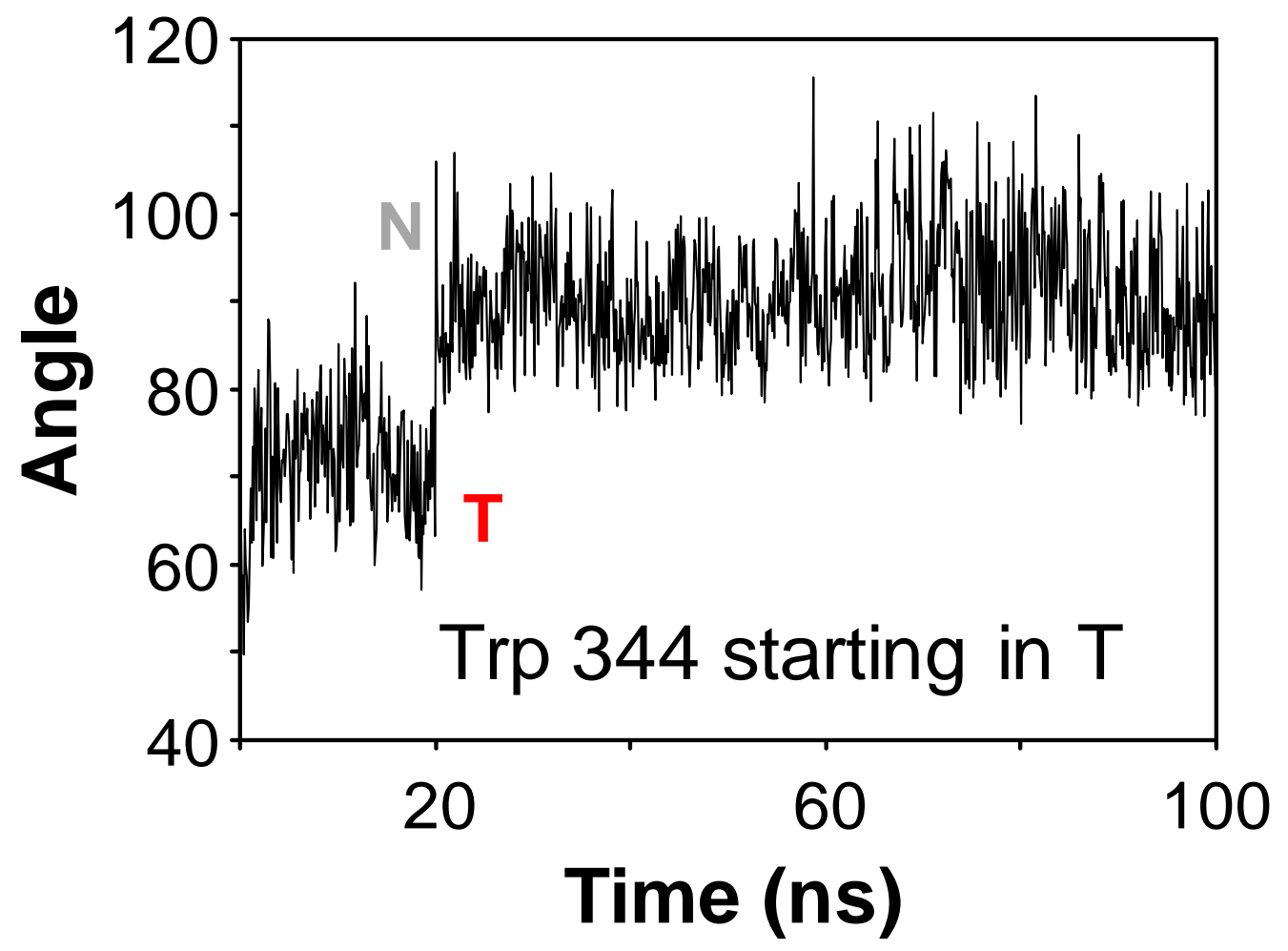

Supplemental Figure 9, related to Figure 6. Time series of the angle of Tryptophan 344 through a molecular dynamics simulation of the $\mathrm{K}_{\mathrm{v}} 7.2 \mathrm{WT}$ CRD forced to start in T configuration. Note that for the first $20 \mathrm{~ns}$, tryptophan 344 remains in $\mathrm{T}$ and then exhibits a conformational change towards the more stable $\mathrm{N}$ configuration. 


\section{Co-translational misfolding in epilepsy}

1. Ambrosino, P.\& Alaimo A.\& Bartollino S.\& Manocchio L.\& De M. M.\& Mosca I.\& GomisPerez C.\& Alberdi A.\& Scambia G.\& Lesca G. et al. Epilepsy-causing mutations in Kv7.2 C-terminus affect binding and functional modulation by calmodulin. Biochim. Biophys. Acta 1852, 1856-1866 (2015).

2. Alaimo, A.\& Gomez-Posada J. C.\& Aivar P.\& Etxeberria A.\& Rodriguez-Alfaro J. A.\& Areso P.\& Villarroel A. Calmodulin activation limits the rate of KCNQ2 $\mathrm{K}^{+}$channel exit from the endoplasmic reticulum. J. Biol. Chem. 284, 20668-20675 (2009).

3. Soldovieri, M. V.\& Miceli F.\& Taglialatela M. Driving with no brakes: molecular pathophysiology of Kv7 potassium channels. Physiology. (Bethesda. ) 26, 365-376 (2011).

4. Maljevic, S., Lerche H. Potassium channel genes and benign familial neonatal epilepsy. Prog. Brain Res. 213, 17-53 (2014).

752

753

754

755

756

757

758

759

760

761

762

763

764

5. Zhang, J.\& Kim E. C.\& Chen C.\& Procko E.\& Pant S.\& Lam K.\& Patel J.\& Choi R.\& Hong M.\& Joshi D. et al. Identifying mutation hotspots reveals pathogenetic mechanisms of KCNQ2 epileptic encephalopathy. Sci. Rep. 10, 4756 (2020).

6. Greene, D. L., Hoshi N. Modulation of Kv7 channels and excitability in the brain. Cell Mol. Life Sci. 74, 495-508 (2017).

7. Gomis-Perez, C.\& Urrutia J.\& Marce-Grau A.\& Malo C.\& Lopez-Laso E.\& Felipe-Rucian A.\& Raspall-Chaure M.\& Macaya A.\& Villarroel A. Homomeric Kv7.2 current suppression is a common feature in KCNQ2 epileptic encephalopathy. Epilepsia 60, 139-148 (2019).

8. Chung, H. J.\& Jan Y. N.\& Jan L. Y. Polarized axonal surface expression of neuronal KCNQ channels is mediated by multiple signals in the KCNQ2 and KCNQ3 C-terminal domains. Proc. Natl. Acad. Sci. USA 103, 8870-8875 (2006).

9. Adams, P. The discovery of the sub-threshold currents $\mathrm{M}$ and $\mathrm{Q} / \mathrm{H}$ in central neurons. Brain Res. 1645, 38-41 (2016).

10. Soldovieri, M. V.\& Cilio M. R.\& Miceli F.\& Bellini G.\& Miraglia d. G.\& Castaldo P.\& Hernandez C. C.\& Shapiro M. S.\& Pascotto A.\& Annunziato L. et al. Atypical gating of Mtype potassium channels conferred by mutations in uncharged residues in the $\mathrm{S} 4$ region of KCNQ2 causing benign familial neonatal convulsions. J. Neurosci. 27, 4919-4928 (2007).

11. Soldovieri, M. V.\& Ambrosino P.\& Mosca I.\& De M. M.\& Moretto E.\& Miceli F.\& Alaimo A.\& Iraci N.\& Manocchio L.\& Medoro A. et al. Early-onset epileptic encephalopathy caused by a reduced sensitivity of Kv7.2 potassium channels to phosphatidylinositol 4,5bisphosphate. Sci. Rep. 6, 38167 (2016). 


\section{Co-translational misfolding in epilepsy}

12. Urrutia, J.\& Aguado A.\& Muguruza-Montero A.\& Nunez E.\& Malo C.\& Casis O.\& Villarroel A. The Crossroad of Ion Channels and Calmodulin in Disease. Int. J Mol. Sci. 20, (2019).

13. Kim, E. C.\& Zhang J.\& Pang W.\& Wang S.\& Lee K. Y.\& Cavaretta J. P.\& Walters J.\& Procko E.\& Tsai N. P.\& Chung H. J. Reduced axonal surface expression and phosphoinositide sensitivity in Kv7 channels disrupts their function to inhibit neuronal excitability in Kcnq2 epileptic encephalopathy. Neurobiol. Dis. 118, 76-93 (2018).

14. Sachyani, D.\& Dvir M.\& Strulovich R.\& Tria G.\& Tobelaim W.\& Peretz A.\& Pongs O.\& Svergun D.\& Attali B.\& Hirsch J. A. Structural Basis of a Kv7.1 Potassium Channel Gating Module: Studies of the Intracellular C-Terminal Domain in Complex with Calmodulin. Structure. 22, 1582-1594 (2014).

15. Bernardo-Seisdedos, G.\& Nunez E.\& Gomis C.\& Malo C.\& Villarroel A.\& Millet O. Structural basis and energy landscape for the $\mathrm{Ca}^{2+}$ gating and calmodulation of the Kv7.2 K+ channel. Proc. Natl. Acad. Sci. U. S. A 115, 2395-2400 (2018).

16. Yus-Nájera, E.\& Santana-Castro I.\& Villarroel A. The identification and characterization of a noncontinuous calmodulin-binding site in noninactivating voltage-dependent KCNQ potassium channels. J. Biol. Chem. 277, 28545-28553 (2002).

17. Nunez, E.\& Muguruza-Montero A.\& Villarroel A. Atomistic Insights of Calmodulin Gating of Complete Ion Channels. Int. J. Mol. Sci. 21, (2020).

18. Alaimo, A.\& Alberdi A.\& Gomis-Perez C.\& Fernandez-Orth J.\& Gomez-Posada J. C.\& Areso P.\& Villarroel A. Cooperativity between calmodulin-binding sites in Kv7.2 channels. J. Cell Sci. 126, 244-253 (2013).

19. Alaimo, A.\& Alberdi A.\& Gomis-Perez C.\& Fernandez-Orth J.\& Bernardo-Seisdedos G.\& Malo C.\& Millet O.\& Areso P.\& Villarroel A. Pivoting between Calmodulin Lobes Triggered by Calcium in the Kv7.2/Calmodulin Complex. PLOS. ONE. 9, e86711 (2014).

20. Chang, A.\& Abderemane-Ali F.\& Hura G. L.\& Rossen N. D.\& Gate R. E.\& Minor D. L., Jr. A Calmodulin C-Lobe $\mathrm{Ca}^{2+}$-Dependent Switch Governs Kv7 Channel Function. Neuron 97, 836-852 (2018).

21. Archer, C. R.\& Enslow B. T.\& Taylor A. B.\& De I. R., V\& Bhattacharya A.\& Shapiro M. S. A mutually induced conformational fit underlies $\mathrm{Ca}^{2+}$-directed interactions between calmodulin and the proximal C terminus of KCNQ4 K+ channels. J Biol. Chem. 294, 60946112 (2019).

22. Bal, M.\& Zaika O.\& Martin P.\& Shapiro M. S. Calmodulin binding to M-type $\mathrm{K}^{+}$channels assayed by TIRF/FRET in living cells. J. Physiol 586, 2307-2320 (2008).

23. Gamper, N., Shapiro M. S. Calmodulin mediates $\mathrm{Ca}^{2+}$-dependent modulation of M-type $\mathrm{K}^{+}$channels. J. Gen. Physiol. 122, 17-31 (2003).

24. Kosenko, A., Hoshi N. A Change in Configuration of the Calmodulin-KCNQ Channel Complex Underlies $\mathrm{Ca}^{2+}$-Dependent Modulation of KCNQ Channel Activity. PLOS. ONE. 8, e82290 (2013). 


\section{Co-translational misfolding in epilepsy}

25. Kang, S.\& Xu M.\& Cooper E. C.\& Hoshi N. Channel anchored protein kinase CK2 and protein phosphatase 1 reciprocally regulate KCNQ2-containing M-channels via phosphorylation of calmodulin. J. Biol. Chem. 289, 11536-11544 (2014).

26. Tobelaim, W. S.\& Dvir M.\& Lebel G.\& Cui M.\& Buki T.\& Peretz A.\& Marom M.\& Haitin Y.\& Logothetis D. E.\& Hirsch J. A. et al. Competition of calcified calmodulin N lobe and $\mathrm{PIP}_{2}$ to an LQT mutation site in Kv7.1 channel. Proc. Natl. Acad. Sci. U. S. A 114, E869E878 (2017).

27. Soldovieri, M. V.\& Castaldo P.\& Iodice L.\& Miceli F.\& Barrese V.\& Bellini G.\& del Giudice E. M.\& Pascotto A.\& Bonatti S.\& Annunziato L. et al. Decreased subunit stability as a novel mechanism for potassium current impairment by a KCNQ2 C terminus mutation causing benign familial neonatal convulsions. J. Biol. Chem. 281, 418-428 (2006).

28. Maljevic, S.\& Naros G.\& Yalcin O.\& Blazevic D.\& Loeffler H.\& Caglayan H.\& Steinlein O. K.\& Lerche H. Temperature and pharmacological rescue of a folding-defective, dominant-negative Kv7.2 mutation associated with neonatal seizures. Hum. Mutat. 32, E2283-E2293 (2011).

29. Hartl, F. U. Protein Misfolding Diseases. Annu. Rev. Biochem. 86, 21-26 (2017).

30. Liutkute, M.\& Samatova E.\& Rodnina M. V. Cotranslational Folding of Proteins on the Ribosome. Biomolecules. 10, (2020).

31. Soldovieri, M. V.\& Boutry-Kryza N.\& Milh M.\& Doummar D.\& Heron B.\& Bourel E.\& Ambrosino P.\& Miceli F.\& De M. M.\& Dorison N. et al. Novel KCNQ2 and KCNQ3 mutations in a large cohort of families with benign neonatal epilepsy: first evidence for an altered channel regulation by syntaxin-1A. Hum. Mutat. 35, 356-367 (2014).

32. Cavaretta, J. P.\& Sherer K. R.\& Lee K. Y.\& Kim E. H.\& Issema R. S.\& Chung H. J. Polarized axonal surface expression of neuronal KCNQ potassium channels is regulated by calmodulin interaction with KCNQ2 subunit. PLOS. ONE. 9, e103655 (2014).

33. Etxeberria, A.\& Aivar P.\& Rodriguez-Alfaro J. A.\& Alaimo A.\& Villace P.\& Gomez-Posada J. C.\& Areso P.\& Villarroel A. Calmodulin regulates the trafficking of KCNQ2 potassium channels. FASEB J. 22, 1135-1143 (2008).

34. Alberdi, A.\& Gomis-Perez C.\& Bernardo-Seisdedos G.\& Alaimo A.\& Malo C.\& Aldaregia J.\& Lopez-Robles C.\& Areso P.\& Butz E.\& Wahl-Schott C. et al. Uncoupling PIP $2^{-}$ calmodulin regulation of Kv7.2 channels by an assembly de-stabilizing epileptogenic mutation. J. Cell Sci. 128, 4014-4023 (2015).

35. Butz, E. S.\& Ben-Johny M.\& Shen M.\& Yang P. S.\& Sang L.\& Biel M.\& Yue D. T.\& WahlSchott C. Quantifying macromolecular interactions in living cells using FRET two-hybrid assays. Nat. Protoc. 11, 2470-2498 (2016).

36. Ben-Johny, M.\& Yue D. N.\& Yue D. T. Detecting stoichiometry of macromolecular complexes in live cells using FRET. Nat. Commun. 7, 13709 (2016).

37. Haitin, Y., Attali B. The C-terminus of Kv7 channels: a multifunctional module. J. Physiol 3, 1803-1810 (2008). 


\section{Co-translational misfolding in epilepsy}

38. Strulovich, R.\& Tobelaim W. S.\& Attali B.\& Hirsch J. A. Structural Insights into the MChannel Proximal C-Terminus/Calmodulin Complex. Biochemistry 55, 5353-5365 (2016).

39. Gomis-Perez, C.\& Alaimo A.\& Fernandez-Orth J.\& Alberdi A.\& Aivar-Mateo P.\& Bernardo-Seisdedos G.\& Malo C.\& Areso P.\& Felipe A.\& Villarroel A. Unconventional calmodulin anchoring site within the AB module of Kv7.2 channels. J Cell Sci. 128, 31553163 (2015).

40. Sun, J., MacKinnon R. Cryo-EM Structure of a KCNQ1/CaM Complex Reveals Insights into Congenital Long QT Syndrome. Cell 169, 1042-1050 (2017).

41. Klee, C. B.\& Crouch T. H.\& Richman P. G. Calmodulin. Annu. Rev. Biochem. 49, 489-515 (1980).

42. Ismail, N.\& Hedman R.\& Schiller N.\& von H. G. A biphasic pulling force acts on transmembrane helices during translocon-mediated membrane integration. Nat. Struct. Mol. Biol. 19, 1018-1022 (2012).

43. Nilsson, O. B.\& Hedman R.\& Marino J.\& Wickles S.\& Bischoff L.\& Johansson M.\& MullerLucks A.\& Trovato F.\& Puglisi J. D.\& O'Brien E. P. et al. Cotranslational Protein Folding inside the Ribosome Exit Tunnel. Cell Rep. 12, 1533-1540 (2015).

44. Marino, J.\& von H. G.\& Beckmann R. Small protein domains fold inside the ribosome exit tunnel. FEBS Lett. 590, 655-660 (2016).

45. Farias-Rico, J. A.\& Ruud S. F.\& Myronidi I.\& Fruhauf M.\& von H. G. Effects of protein size, thermodynamic stability, and net charge on cotranslational folding on the ribosome. Proc. Natl. Acad. Sci. U. S. A 115, E9280-E9287 (2018).

46. Kemp, G.\& Kudva R.\& de la Rosa A.\& von H. G. Force-Profile Analysis of the Cotranslational Folding of HemK and Filamin Domains: Comparison of Biochemical and Biophysical Folding Assays. J. Mol. Biol. 431, 1308-1314 (2019).

47. Barlow, K. A.\& Conchuir O.\& Thompson S.\& Suresh P.\& Lucas J. E.\& Heinonen M.\& Kortemme T. Flex ddG: Rosetta Ensemble-Based Estimation of Changes in ProteinProtein Binding Affinity upon Mutation. J. Phys. Chem. B 122, 5389-5399 (2018).

48. Alford, R. F.\& Leaver-Fay A.\& Jeliazkov J. R.\& O'Meara M. J.\& DiMaio F. P.\& Park H.\& Shapovalov M. V.\& Renfrew P. D.\& Mulligan V. K.\& Kappel K. et al. The Rosetta All-Atom Energy Function for Macromolecular Modeling and Design. J. Chem. Theory. Comput. 13, 3031-3048 (2017).

49. Kumar, S.\& Rosenberg J. M.\& Bouzida D.\& Swendsen R. H.\& Kollman P. A. The weighted histogram analysis method for free-energy calculations on biomolecules. I. The method. J. Comput. Chem. 13, 1011-1021 (1992).

50. Ghosh, S.\& Nunziato D. A.\& Pitt G. S. KCNQ1 assembly and function is blocked by longQT syndrome mutations that disrupt interaction with calmodulin. Circ. Res. 98, 10481054 (2006).

51. Shamgar, L.\& Haitin Y.\& Yisharel I.\& Malka E.\& Schottelndreier H.\& Peretz A.\& Paas Y.\& Attali B. KCNE1 constrains the voltage sensor of Kv7.1 K+ channels. PLOS. ONE. 3, e1943 (2008). 


\section{Co-translational misfolding in epilepsy}

892

893

894

895

896

897

898

899

900

901

902

903

904

905

906

907

908

909

910

911

912

913

914

915

916

917
52. Sander, I. M.\& Chaney J. L.\& Clark P. L. Expanding Anfinsen's principle: contributions of synonymous codon selection to rational protein design. J Am. Chem. Soc. 136, 858-861 (2014).

53. Dobson, C. M. Protein folding and misfolding. Nature 426, 884-890 (2003).

54. Woolhead, C. A.\& McCormick P. J.\& Johnson A. E. Nascent membrane and secretory proteins differ in FRET-detected folding far inside the ribosome and in their exposure to ribosomal proteins. Cell 116, 725-736 (2004).

55. Bhushan, S.\& Gartmann M.\& Halic M.\& Armache J. P.\& Jarasch A.\& Mielke T.\& Berninghausen O.\& Wilson D. N.\& Beckmann R. alpha-Helical nascent polypeptide chains visualized within distinct regions of the ribosomal exit tunnel. Nat. Struct. Mol. Biol. 17, 313-317 (2010).

56. Nissley, D. A., O'Brien E. P. Structural Origins of FRET-Observed Nascent Chain Compaction on the Ribosome. J. Phys. Chem. B 122, $9927-9937$ (2018).

57. Frydman, J.\& Erdjument-Bromage H.\& Tempst P.\& Hartl F. U. Co-translational domain folding as the structural basis for the rapid de novo folding of firefly luciferase. Nat. Struct. Biol. 6, 697-705 (1999).

58. Best, R. B., Hummer G. Biochemistry. Unfolding the secrets of calmodulin. Science 323, 593-594 (2009).

59. Junker, J. P.\& Ziegler F.\& Rief M. Ligand-dependent equilibrium fluctuations of single calmodulin molecules. Science 323, 633-637 (2009).

60. Westerlund, A. M., Delemotte L. Effect of $\mathrm{Ca} 2+$ on the promiscuous target-protein binding of calmodulin. PLoS. Comput. Biol. 14, e1006072 (2018).

61. Huang, J., Mackerell A. D., Jr. CHARMM36 all-atom additive protein force field: validation based on comparison to NMR data. J. Comput. Chem. 34, 2135-2145 (2013). 